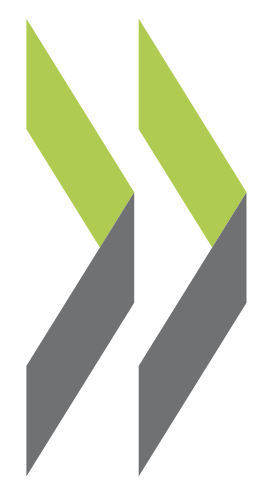

OECD Economics Department Working Papers No. 527

Upgrading Japan's Innovation System to Sustain Economic Growth

\author{
Randall S. Jones, \\ Tadashi Yokoyama
}


Organisation de Coopération et de Développement Economiques

ECONOMICS DEPARTMENT

English text only

UPGRADING JAPAN'S INNOVATION SYSTEM TO SUSTAIN ECONOMIC GROWTH ECONOMICS DEPARTMENT WORKING PAPER No. 527

By Randall S. Jones and Tadashi Yokoyama

All Economics Department Working Papers are available through OECD's Internet Website at www.oecd.org/eco/working_papers 


\section{ABSTRACT/RÉSUMÉ \\ Upgrading Japan's innovation system to sustain economic growth}

Increasing productivity growth through innovation is a key to raising living standards. Although $R \& D$ intensity in Japan is the third highest in the OECD area, the benefits do not appear to have been commensurate with the level of investment. The innovation system, which developed during the catchingup process, is largely input-driven and focused on incremental innovation based on closed and stable corporate and employment systems. However, this approach is less appropriate in the current global environment that favours risk-taking and a more open system relying on external linkages. To improve the innovation system, a broad-based strategy is needed, including a reform of framework conditions in the product and labour markets to strengthen competition and mobility, enhance international R\&D links and improve the environment for venture business. Education and public research should be upgraded through stronger competition. The effectiveness of science and technology policy should be increased by strengthening its link to economic framework policies.

This Working Paper relates to the 2006 OECD Economic Survey of Japan (www.oecd.org/eco/surveys/japan).

JEL classification: $\mathrm{I} 2, \mathrm{O} 39, \mathrm{O} 31, \mathrm{O} 33, \mathrm{O} 34, \mathrm{O} 38, \mathrm{O} 33$.

Keywords: Innovation, R\&D system, science and technology, third Basic Plan, technological change, ICT sector, patents, intellectual property, product market competition, service sector, regulatory reform, venture capital, tertiary education, Japan.

\section{Améliorer le système d'innovation pour assurer une croissance économique durable}

Accroître la productivité grâce à l'innovation est l'un des principaux moyens d'élever le niveau de vie. Alors que le Japon se place au troisième rang des pays de l'OCDE pour ce qui est de l'intensité de R-D, les résultats obtenus ne paraissent pas à la hauteur des investissements. Le système d'innovation, qui s'est développé au cours du processus de rattrapage, est orienté dans une large mesure par l'investissement et met l'accent sur les innovations progressives fondées sur des structures d'entreprise et d'emploi fermées et stables. Or, cette approche est moins adaptée à l'environnement mondial actuel, qui favorise la prise de risque et des systèmes plus ouverts fondés sur des liens externes. Pour améliorer le système d'innovation, il importe de mettre en œuvre une vaste stratégie consistant notamment à réformer les conditions cadres qui régissent les marchés de produits et du travail, afin de renforcer la concurrence et la mobilité, de favoriser les relations internationales en matière de R-D et d'améliorer l'environnement des entreprises innovantes. Il faudrait par ailleurs rendre l'éducation et la recherche publique plus performantes grâce à une concurrence plus intense. Il y aurait lieu également d'accroître l'efficacité de la politique scientifique et technologique en renforçant ses liens avec les politiques économiques générales.

Ce Document de travail se rapporte à l’Étude économique du Japon 2006 (www.oecd.org/eco/etudes/japon).

Classification JEL : I2, O39, O31, O33, O34, O38, O53.

Mots clés: Innovation, système de R-D, activités scientifiques et technologiques, le troisième Plan cadre, secteur TIC, brevets, propriété intellectuelle, concurrence sur les marchés, les services, reforme réglementaire, entreprises à risqué, enseignement supérieur, Japon.

\section{Copyright OECD 2006}

Application for permission to reproduce or translate all, or part of, this material should be made to: Head of Publications Service, OECD, 2 rue André-Pascal, 75775 Paris Cedex 16, France. 


\section{TABLE OF CONTENTS}

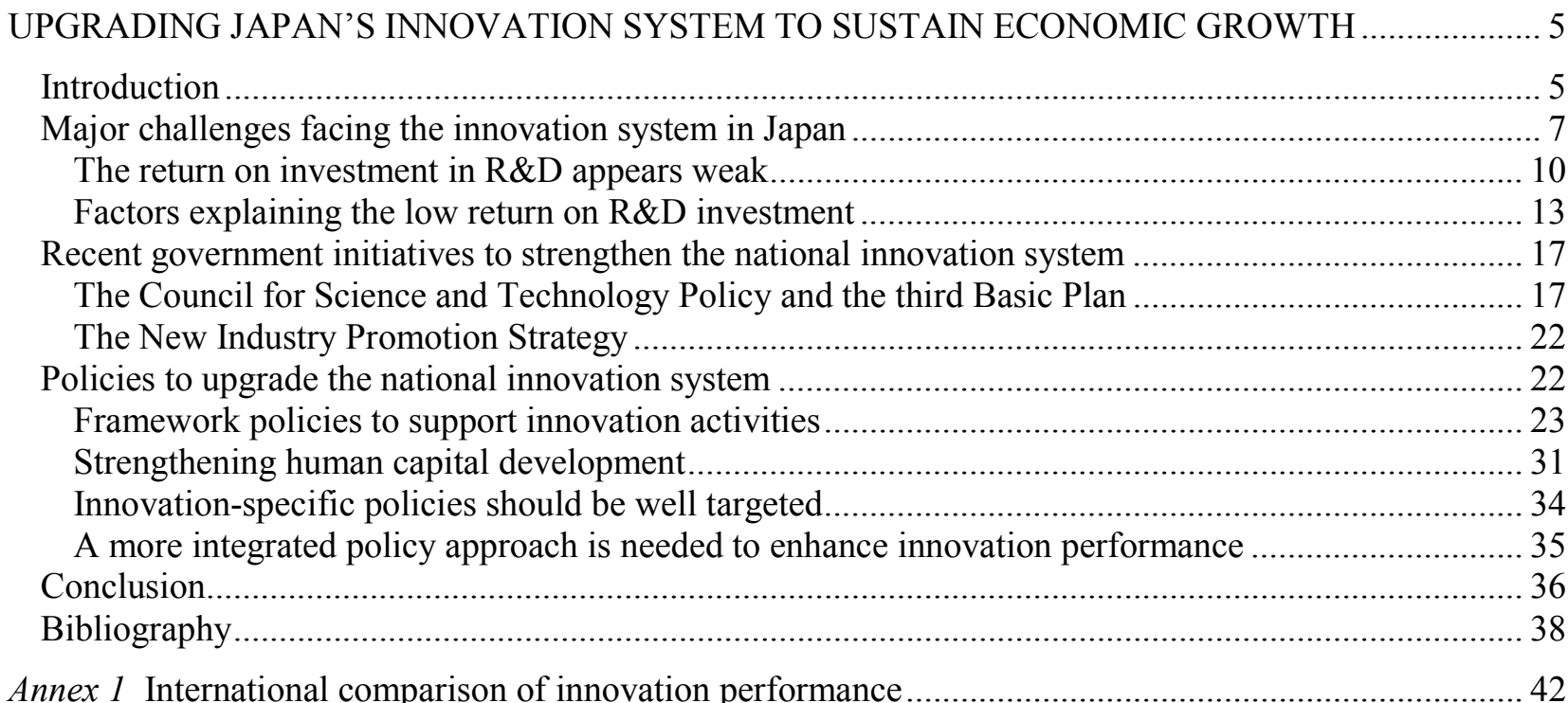

\section{Tables}

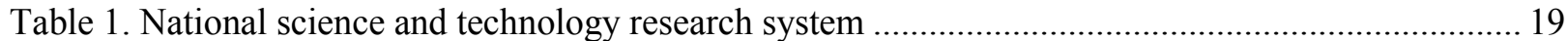

Table 2. Reform proposals accepted under the special zone initiative................................................. 28

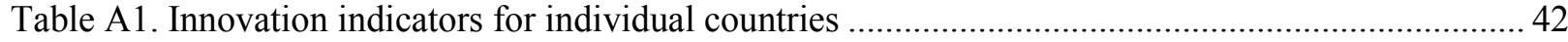

\section{Figures}

Figure 1. An international comparison of trends in R\&D intensity ................................................... 7

Figure 2. International comparison of Japan's innovation performance.............................................. 9

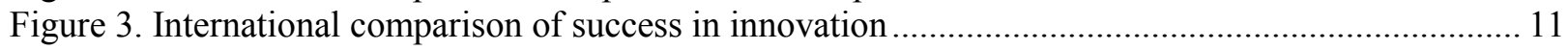

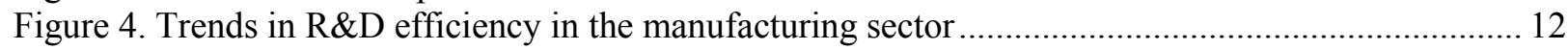

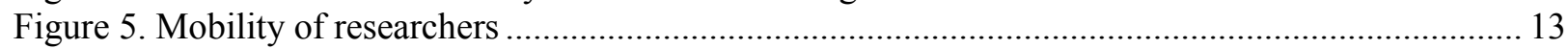

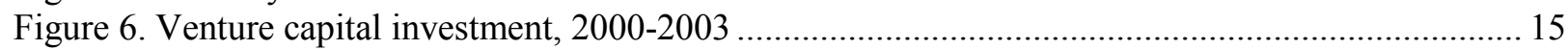

Figure 7. Regulatory conditions in seven non-manufacturing sectors .............................................. 16

Figure 8. Comparison of productivity in the Japanese services sector................................................... 16

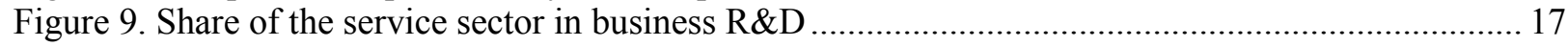

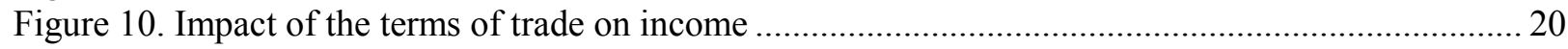

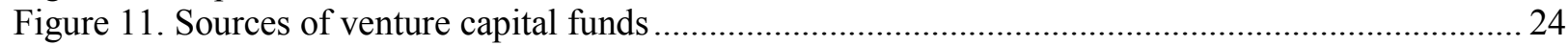

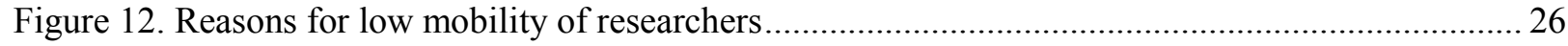

Figure 13. Comparison of productivity in the retail sector by type of stores .......................................... 30

Figure 14. Percentage of students using a computer at least a few times each week.............................. 32

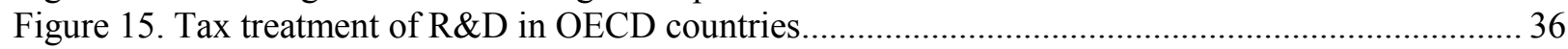




\section{ECO/WKP(2006)55}

\section{Boxes}

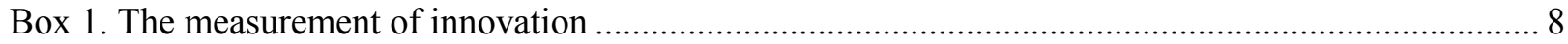

Box 2. An international comparison of Japan's innovation system ...................................................... 8

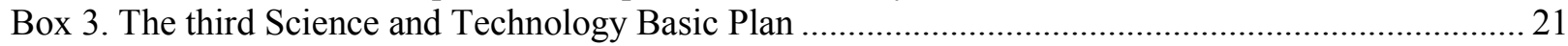

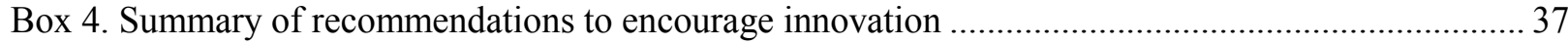


ECO/WKP(2006)55

\title{
UPGRADING JAPAN'S INNOVATION SYSTEM TO SUSTAIN ECONOMIC GROWTH
}

\author{
Randall S. Jones \& Tadashi Yokoyama ${ }^{1}$
}

\section{Introduction}

1. Innovation - the successful commercial development and application of new knowledge - has been an important source of economic growth in Japan, as in other OECD countries. ${ }^{2}$ Innovation leads to higher income growth through productivity gains and by creating new demand (Aoki and Yoshikawa, 2002). From the 1960s until the early 1990s, Japanese innovation focused on imitating and improving products and processes that had been developed in other countries, thereby limiting costs. ${ }^{3}$ Process innovation and incremental product innovation were an important aspect of this process, resulting in technological advances in manufacturing that were exploited by large-scale investment (OECD, 2005e). Incremental innovation was achieved through a complicated interaction and integration of skills (suriawase) within each company and within closed networks of companies based on the internal accumulation of company-specific knowledge (Goto, 2000). The system was supported by a stable and self-contained business system, built on a rigid employment structure of seniority-based promotion, lifetime employment and in-house training. The self-contained structure was also encouraged by an extensive indirect financing system, centred on each company's "main bank". In addition, enterprises pursued selfcontained R\&D strategies by establishing their own research institutes, reflecting in part their low expectations of higher education in Japan, but thereby further weakening domestic and international linkages. ${ }^{4}$

2. However, as Japan was completing the catching-up process, international competition was shifting to a new stage of industry-based knowledge and open networks. Basic research tends to be outsourced to universities and external research organisations with specialised expertise, while start-up companies play an increasingly important role in risky investment. ${ }^{5}$ The importance of company-specific knowledge and experience accumulated and shared internally is being replaced by more specialised,

1. Randall S. Jones is head of the Japan/Korea Desk in the Economics Department of the OECD and Tadashi Yokoyama is an economist on that desk. This paper is based largely on material from the OECD Economic Survey of Japan published in July 2006 under the authority of the Economic and Development Review Committee (EDRC). The authors would like to thank Andrew Dean, Val Koromzay, Willi Leibfritz and Taesik Yoon for valuable comments on earlier drafts. Special thanks go to Roselyne Jamin for technical assistance and to Nadine Dufour and Lillie Kee for technical preparation.

2. For example, The Sources of Economic Growth in OECD Counties (OECD, 2003c) found a positive link between R\&D intensity in the private sector and the level of per capita GDP.

3. See Sakakibara and Tsujimoto (2003) for a description of this process.

4. See Sakakibara (2003), Sakakibara and Tsujimoto (2003), and OECD (2005e). The number of private research institutes in science and engineering increased from 196 (22.3\% of total science and engineering research institutes including national and local public institutes) in 1975 to 239 (25.8\%) in 1980, 485 $(41.5 \%)$ in 1990 and 496 (42.7\%) in 1995, before decreasing to 384 (42.0\%) in 2003 (Kondo, 2006).

5. For example, the share of post-genome patents filed by start-ups is $12 \%$ in Japan, compared with $38 \%$ in the United States (OECD, 2005e). 
codified, module-based and open-network type knowledge in the era of rapid technological progress and globalisation and this trend is expected to continue (OECD, 2005e). Although the government and the business sector recognised by the end of the 1980s the importance of shifting from a catching-up process to a system based on fundamental product innovation through creativity, Japan has been slow to adjust its corporate system and industrial structure to this new environment. Moreover, the concept of management of technology, including closer interaction between $R \& D$ and marketing, is weak in a large proportion of Japanese firms. ${ }^{6}$

3. R\&D spending in Japan increased markedly during the 1990s despite economic stagnation. The high level of investment in R\&D is reflected in some positive outcomes that are supporting Japan's international competitiveness in some key sectors. According to the US National Science Foundation, Japan's share of world exports of seven key high-tech manufactured products in 2001 was $10 \%$, second only to the US share of $17 \%{ }^{7}$ The steady increase in Japan's net technological balance of payments ${ }^{8}$ also reflects a strengthening of its innovation activities, which is mirrored in the rankings of Japan's R\&D performance in various international surveys. ${ }^{9}$ However, a number of industries have lost competitiveness, particularly in sectors characterised by module-based production, such as portable computers, semiconductors, telecommunications equipment and bio-industry (Ando and Motohashi, 2003).

4. Moreover, the return on investment in knowledge did not meet expectations. Indeed, the economic malaise of the 1990s raised the question of why the OECD country with one of the highest R\&D intensities had such disappointingly low rates of productivity growth. Looking ahead, innovation to boost productivity is a key to sustaining increases in living standards as the decline in the working-age population accelerates. This paper examines the current innovation system in Japan and highlights a few key challenges:

- Japanese innovation activities, which developed as part of the catching-up process, need to be modernised and internationalised to raise their efficiency.

- The concept of innovation in Japan is generally equated with pure scientific progress, focusing government policies on science and technology. Weak links between science and technology policies and framework conditions, such as education, the product and labour markets, and competition policy, have led to a failure to maximise the return on $R \& D$ and to strengthen innovation, particularly in the service sector, which is a key to sustaining economic growth.

5. This paper begins with an assessment of Japan's innovation performance, followed by an analysis of recent government initiatives in this area. The following section examines policies to improve the innovation system, including changes in framework conditions, notably venture capital, the labour market and product market competition, as well as human capital development and innovation-specific policies. The paper concludes with a set of policy recommendations (Box 4).

6. See, for example, Goto (2000), Motohashi (2005), Ando and Motohashi (2002) and OECD (2005e).

7. The seven sectors are: aerospace; computers and office machinery; communications equipment; pharmaceuticals; medical instruments; precision instruments; and optical instruments (National Science Foundation, 2004).

8. This measure of international technology transfers includes licence fees, royalties and purchases of patents, research and technical aid. Unlike R\&D outlays, these are payments for production-ready technology.

9. The US Council on Competitiveness (1999) ranked Japan in their outlook for 2005 at the top of its index of international patents. In addition, Japan has remained first or second in the IMD's ranking of science infrastructure, despite a significant deterioration in its overall ranking for national competitiveness during the $1990 \mathrm{~s}$. 


\section{Major challenges facing the innovation system in Japan}

6. While innovation is a key factor driving economic growth in the long run, it is difficult to measure (Box 1). A common method is to look at R\&D performance, as this is a basic source of innovation. Japan recorded the third highest R\&D intensity in the OECD area at 3.2\% of GDP in 2003, compared with $2.6 \%$ in the United States and $2.0 \%$ in the EU (Figure 1 ). ${ }^{10}$ Japan's high ranking is primarily due to the business sector, whose R\&D intensity was also the third highest in the OECD, accounting for three-quarters of total $R \& D$ expenditures (Box 2). At the same time, $R \& D$ outlays by the government and higher education as a share of GDP were also above the OECD average. Moreover, public R\&D spending during the past decade rose at a $6 \%$ real annual average rate, compared with an OECD average of $3.5 \%$, thus contributing to the increase in R\&D intensity in Japan. Growth in the number of researchers has also outstripped the OECD average during the past decade. In sum, despite depressed economic conditions, the level of R\&D inputs has increased significantly since 1990 from already high levels, placing Japan near the top of OECD countries.

Figure 1. International comparison of trends in R\&D intensity Gross domestic expenditure on R\&D as per cent of GDP

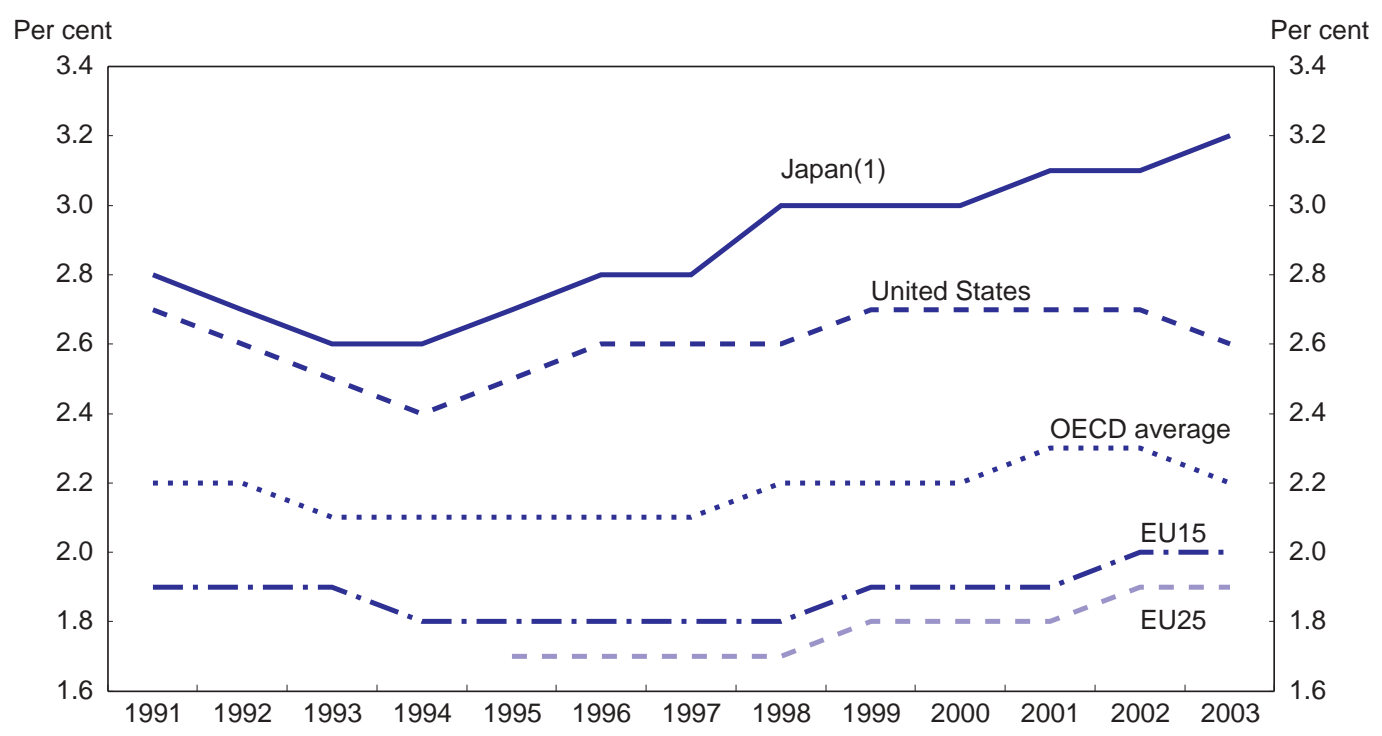

1. The data for Japan prior to 1996 are adjusted to make them comparable to other countries. Until 1995, Japanese data for R\&D personnel was expressed as the number of persons, rather than in terms of full-time equivalent.

Source: OECD, OECD Science, Technology and Industry Scoreboard 2005.

10. In absolute terms, Japan was the second largest spender on R\&D in the OECD area in 2003 with $17 \%$ of the total, after the United States, which had $42 \%$. The data in this section are from the OECD Science and Technology Scoreboard (OECD, 2005j) unless otherwise indicated. 


\section{Box 1. The measurement of innovation}

Most of the rise in living standards since the industrial revolution has been the result of innovation, through new products and services and by more efficient ways of producing them. Assessing innovation performance remains a challenge, given the lack of direct and comparable measures of innovation outcomes. One way to measure the volume of innovative activity is to look at total and/or private spending on R\&D. However, one limitation is that investment in innovation also includes activities that are not necessarily recorded as formal R\&D spending, such as the purchase of high-tech equipment, training and product testing. Furthermore, the volume of R\&D spending is not sufficient to assess a country's success in innovation. As with all types of investment, it is not only the total amount invested that matters but also how efficiently resources are used. Recent innovation surveys provide some insights into innovation performance, but suffer from response biases that limit cross-country comparability (OECD, 2004b).

A key measure of innovation output is the number of patents issued, although this indicator has a number of weaknesses. First, international comparability is limited by several factors, including substantial variations in the criteria used to grant patents, the filing system and the cost of patenting. One measure that reduces the impact of such factors is the number of triadic patents - patents issued by the United States, Japan and the European Union. Second, the propensity to patent differs across industries, affecting comparisons based on economy-wide data. Third, perhaps more importantly, patents only capture part of innovation output. Many innovations are not patented as companies may prefer to keep commercially sensitive information secret or claim property rights via other means such as trademarks and copyrights. In addition, many patents are never exploited for economic purposes. ${ }^{1}$ The shortcomings of available indicators need to be kept in mind in assessing innovation performance.

1. A survey of 643 major companies in Japan found that patents are not necessarily the key instrument used to obtain exclusive rights over innovative outcomes (Goto, 2000). As for product innovation, advancing the time of initial production was the most effective method $(41 \%)$, followed by patents $(38 \%)$ and possession and administration of production facilities and know-how (33\%). For process innovation, possession and administration of production facilities and know-how was ranked at the top (36\%), followed by hiding technological information $(29 \%)$ and patents (25\%). There are wide differences between industries; in pharmaceuticals, for example, $65 \%$ of firms cited the effectiveness of patents.

\section{Box 2. An international comparison of Japan's innovation system}

\section{Total R\&D spending is high in Japan}

Total R\&D spending in Japan as a share of GDP is significantly above the OECD average (Figure 2, line 1):

- As a share of GDP, R\&D expenditures by the business, government and higher education sectors were each higher than the OECD average in 2003 (lines 2, 3 and 4).

- In terms of the allocation of national R\&D outlays between sectors, the business sector in Japan in 2003 had a relatively large share $(75 \%$ versus an OECD average of $62 \%)$, higher education had a relatively low share (14\% versus $19 \%)$ and the government sector was close to the OECD average (9\% versus $11 \%)$.

- $\quad$ On the funding side, business-sector financing of R\&D - at $2.4 \%$ of GDP - was considerably above the OECD average of $1.4 \%$. Government financing of R\&D matched the OECD average of $0.7 \%$ of GDP. ${ }^{1}$

Japan had the third highest number of researchers relative to total population in the OECD area (line 5), with 10.4 per thousand in 2003, compared with 9.3 in the United States and 5.8 in the European Union. However, Japan's ranking would decline if the number of researchers were adjusted by the time devoted to research, given that Japanese researchers tend to spend more time on non-research activities. As with R\&D spending, about three-quarters of researchers are in the business sector. The expansion of higher education enrolments has also boosted human capital in Japan (line 6): tertiary-level graduates as a percentage of total employment was the second highest in Japan at $41 \%$ in 2003 , compared with an OECD average of $29 \%$. Moreover, the proportion of tertiary degrees in science and engineering (line 7 ) is above the OECD average of $23 \%$. 
Figure 2. International comparison of Japan's innovation performance OECD $=100$, latest available year ${ }^{(1)}$

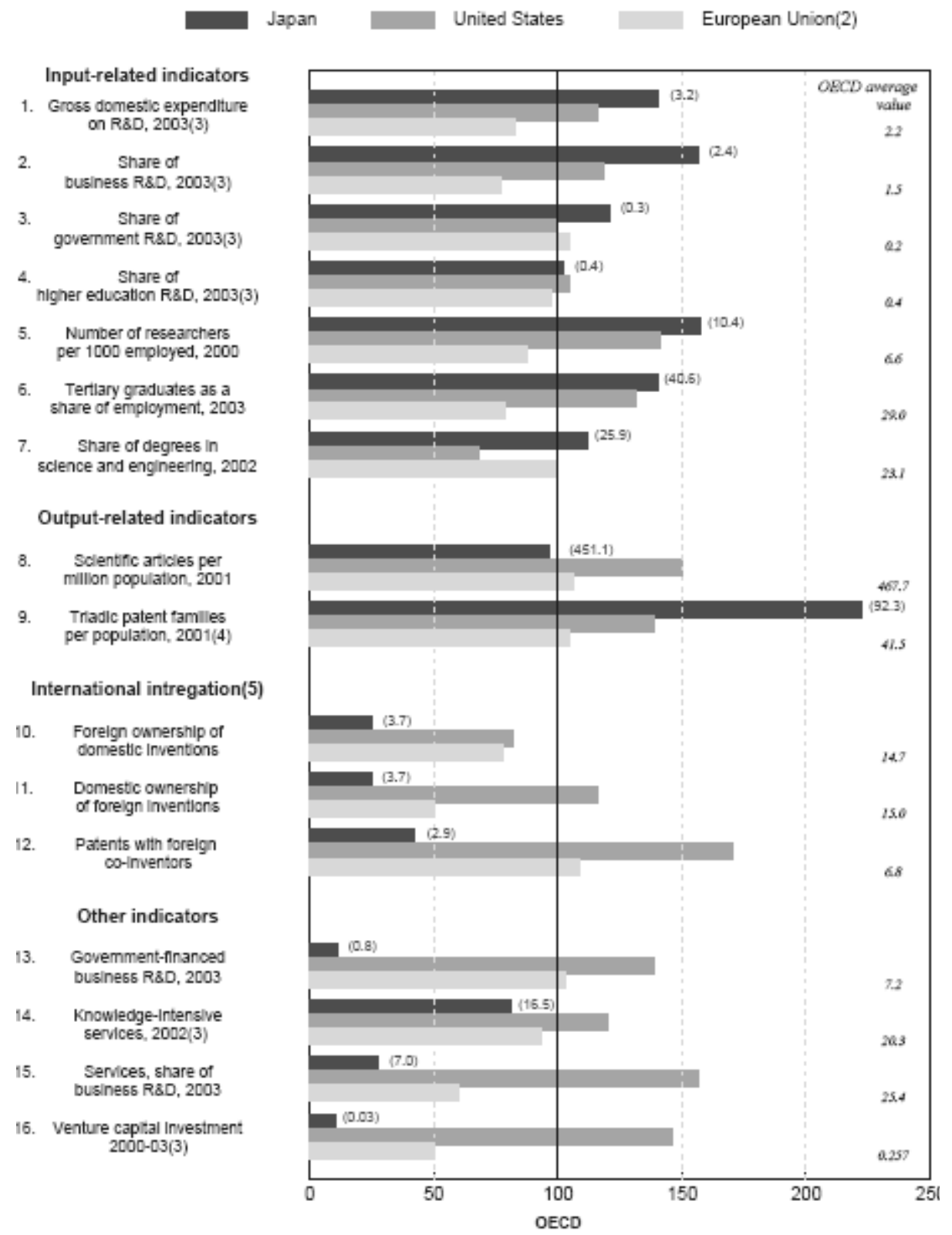

1. See Annex A1 for information on individual countries. The year varies among countries. See the source for information on exact years for individual countries.

2. Does not include all European Union member countries. See Annex A1 for information on which countries are excluded.

3. As per cent of GDP.

4. Patents filed in the United States, Europe and Japan.

5. During the period 1999-2001.

Source: OECD, OECD Science, Technology and Industry Scoreboard 2005.

\section{The return on R\&D investment}

Although its production of scientific articles is growing rapidly, Japan's share of $9 \%$ of the world total in 2001 was well below its contribution to global R\&D and patents. When scientific articles are compared to population, Japan ranks $17^{\text {th }}$ in the OECD area and is the only G-7 country below the OECD average (line 8). In the 19 most industry-relevant scientific disciplines, Japan ranks $18^{\text {th }}$ among 23 OECD countries in publications (OECD, 2005e). Moreover, while US publications show balanced strength across scientific areas, as measured by the number of publications, Japan reports large imbalances between relatively strong fields, such as material science and chemical engineering, and weak fields 
such as biosciences, medicine and pharmaceuticals. On the other hand, Japan's contribution to global patenting is large relative to its population (line 9) and R\&D efforts, accounting for $24 \%$ of all triadic patents in 2001 , compared with around $34 \%$ for both the United States and the European Union, However, a large proportion, as much as two-thirds according to a recent study, are idle - so-called "sleeping patents" (OECD, 2005e). ${ }^{2}$

\section{Japan is the least active in international co-operation in R\&D and patenting}

During the period 1999-2001, Japan was the lowest in the OECD area in each of the measures of international integration shown in Figure 2 (lines 10 to 12). Foreigners owned less than 4\% of domestic inventions in Japan (line 11), well below the $12 \%$ level in the United States and the European Union. The share of patents with foreign co-inventors in Japan was less than 3\%. Foreign affiliates accounted for $4 \%$ of manufacturing R\&D in Japan, substantially below the level of around $18 \%$ in the United States and the European Union.

\section{Weaknesses in the area of R\&D linkages, services and venture capital investment}

International comparisons indicate a number of other weaknesses in Japan's innovation system:

- $\quad$ The linkages between R\&D sectors appear to be weak. For example, the share of government-financed business R\&D in Japan was $0.8 \%$ in 2003 (line 13), the lowest in the OECD, compared with $7 \%$ in the European Union and $10 \%$ in the United States.

- Japan is lagging in the service sector. Knowledge-intensive services accounted for $16.5 \%$ of total value added in 2002 (line 14), well below the European Union at 19\% and the United States at $24 \%$.

- The share of the service sector in business R\&D in Japan was the lowest in the OECD at 7\% (line 15), well below the $15 \%$ in the European Union and $40 \%$ in the United States. The service sector contributed only 0.7 percentage point annually to labour productivity growth during 1995-2003, compared with 1.7 points in the United States.

- Venture capital investment as a percentage of GDP (line 16) in Japan was the second smallest in the OECD area.

1. In other words, the business sector completely financed its R\&D outlays (shown in line 2), while the government funded the R\&D activities of public research institutes (line 3) and higher education (line 4).

2. In Japan, large companies tend to evaluate researchers based on the number of patents they generate, while placing less emphasis on their success in making innovative and risky investments based on those patents (Wakasugi et al., 1995 and Goto, 2000).

\section{The return on investment in $R \& D$ appears weak}

7. The overall output from investment in innovation does not appear to have been commensurate with the large amount of inputs. The Science Council of Japan estimates that efficiency in R\&D in the four priority areas (see below) is around half of that in the United States and major European countries. ${ }^{11}$ In addition, according to a survey of firms in Europe and Japan, the proportion of Japanese companies reporting success in innovation is only $22 \%$, well below the EU average of $41 \%$ (Figure 3 ), although there is a need for caution in evaluating such survey results. Japan ranks slightly below the OECD average in the number of scientific articles per population, even after adjusting for the number of citations, and is weak in the disciplines most relevant to the business sector (Box 2). On the other hand, the National Institute of Science and Technological Policy (NISTEP), a research institute of the Ministry of Education, Culture, Sports, Science and Technology, reported that the number of papers published per university faculty

11. The Science Council of Japan (2005) obtained this result by analysing the relationship between inputs (R\&D expenditure and the number of researchers) and outputs (numbers of papers, citations, patents and exports of high-tech products and technology). The OECD's Committee on Science and Technology Policy is developing indicators to compare $\mathrm{R} \& \mathrm{D}$ performance across countries. 
member in natural science in Japan has almost reached the US level, while the number of papers per R\&D expenditure is higher (NISTEP, 2005).

Figure 3. International comparison of success in innovation

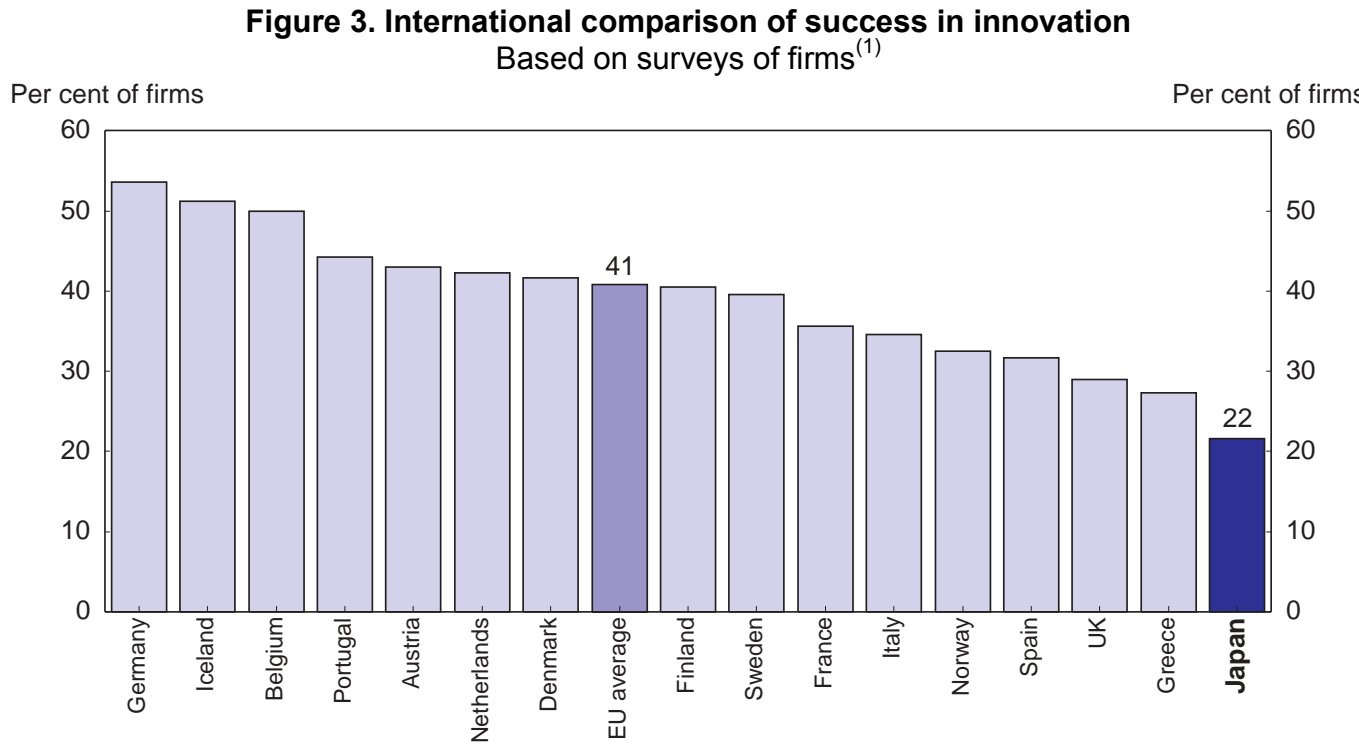

1. The survey period was 1999-2001 for Japan and 1998-2000 for the European countries. The EU average is for the $13 \mathrm{EU}$ countries shown in the figure. This comparison was published in Japan by the Cabinet Office (2005a). There is a need for caution in evaluating such surveys because of the low response rate in Japan.

Source: National Institute of Science and Technology Policy, National Innovation Survey 2003, and Eurostat, Innovation in Europe.

8. Moreover, there is evidence that the impact of R\&D on the economy has weakened during the past decade. A study by the Cabinet Office (2005a) found that the efficiency of private-sector R\&D declined during the 1990s (Figure 4). ${ }^{12}$ In addition, while an OECD report found a positive correlation between changes in business-sector R\&D intensity and multifactor productivity (MFP) growth during the 1980s and 1990s in the OECD area, the fact that Japan recorded a decline in MFP growth despite higher R\&D spending suggests that its investment in innovation was less efficient (OECD, 2001). However, given that productivity growth is affected by cyclical factors, economic stagnation also depressed MFP gains during the 1990s. ${ }^{13}$ In addition, structural problems during the post-bubble period, notably in the financial system, pushed down productivity. ${ }^{14}$ With the cyclical upturn and the removal of structural obstacles through restructuring, the high level of R\&D should now be more effective in boosting productivity growth in the coming years. However, the capacity to innovate depends on successful interactions between a

12. Sakakibara and Tsujimoto (2003) obtained a similar result. Another report by the Cabinet Office (2002) found that the contribution of investment in technology and knowledge to economic growth decelerated in the 1990 s.

13. According to Fukao and Kwon (2003), about half of the $0.43 \%$ decline in TFP growth between the periods 1983-91 and 1991-98 can be explained by the decline in the capital utilisation ratio, which should pick up with sustained economic growth.

14. Nishimura et al., (2003) and Fukao and Kwon (2003) both found that the efficiency of existing firms was lower than that of exiting firms in the late 1990s. According to Nishimura et al. (2003), this phenomenon was more commonly observed among younger and smaller companies and it negatively affected the overall TFP level after 1996. Fukao and Kwon (2003) reported that companies with higher productivity, but in industries with a higher level of debt, tended to exit, perhaps due to the malfunctioning of the financial system, including so-called "evergreening" of loans to keep weak firms in business. 
number of actors and institutions that contribute in different ways to the innovation process (OECD, 2005e). Conditions for a successful national innovation system include:

- $\quad$ Strong industry-science linkages, allowing firms to better exploit the output from public research and helping researchers to better respond to business-sector needs.

- A significant proportion of firms actively engaged in cross-border trade and investment, given that genuinely new products or processes often come from abroad.

- A solid science base, anchored in higher education and research organisations that nurture cutting-edge research and develop skilled human resources in science, technology and engineering.

- A culture of entrepreneurship underpinned by market incentives and conditions that encourage risk-taking activities.

- Appropriate framework conditions, including product market competition and regulation and labour market regulations that encourage both the creation and diffusion of innovation.

- The following section examines Japan's performance in these areas.

Figure 4. Trends in R\&D efficiency in the manufacturing sector

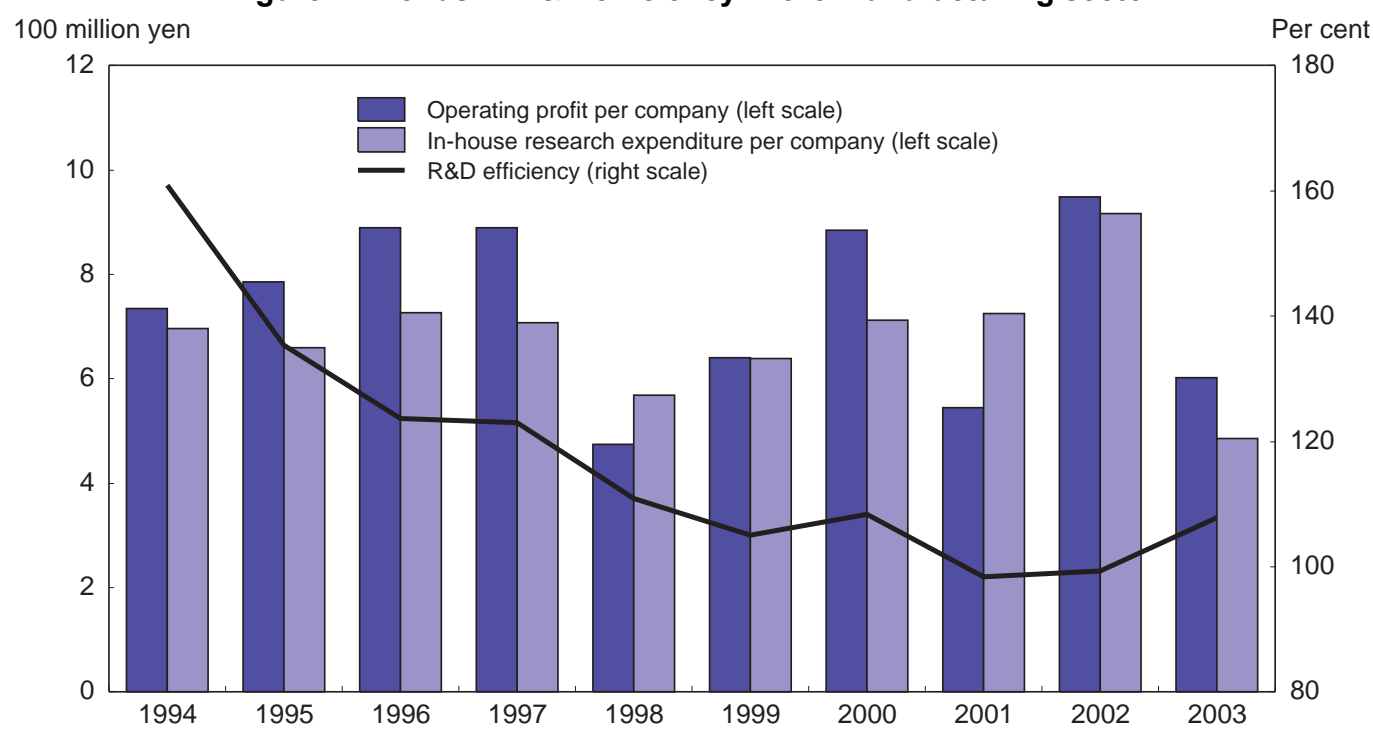

Note: R\&D efficiency in each fiscal year is calculated as (cumulative operating profit per company over the preceding five years)/(cumulative research expenditure per company used in-house over the period five to nine years prior to the given fiscal year). For example, the R\&D efficiency rate in FY 2003 is the cumulative profits between FY 1999-2003 divided by R\&D expenditures between FY 1994-98.

Source: Cabinet Office (2005a), Annual Report on the Japanese Economy and Public Finance 2005. 


\section{Factors explaining the low return on $R \& D$ investment}

Ties between the business sector and research organisations in the public sector are weak

9. Links between firms and research institutes in government and higher education can improve the match between public-sector research and industry needs, thus facilitating the transfer of knowledge to firms. Such links, however, are weak in Japan. For example, business-financed R\&D performed by the government and higher education as a share of GDP are only $40 \%$ and $50 \%$, respectively, of the OECD average. As noted above, many firms prefer to establish their own R\&D centres. Moreover, the movement of researchers among institutes, an effective way to transfer knowledge and technology, is extremely low in Japan, reflecting rigid employment practices. The average number of job changes by researchers in Japan is 0.8 times during their career, significantly less than in some other countries, such as the Netherlands (3.5), Australia (2.6), Germany (2.0) and the United States (1.6) (The Carnegie Foundation for the Advancement of Teaching, 1994). Only $3.7 \%$ of researchers changed their organisational affiliation in FY 2003 (Figure 5). Of the academic researchers who changed jobs, 85\% moved to another academic post and only $6 \%$ went to the business sector.

Figure 5. Mobility of researchers

Number of researchers and job changes within and between organisations in FY $2003^{(1)}$

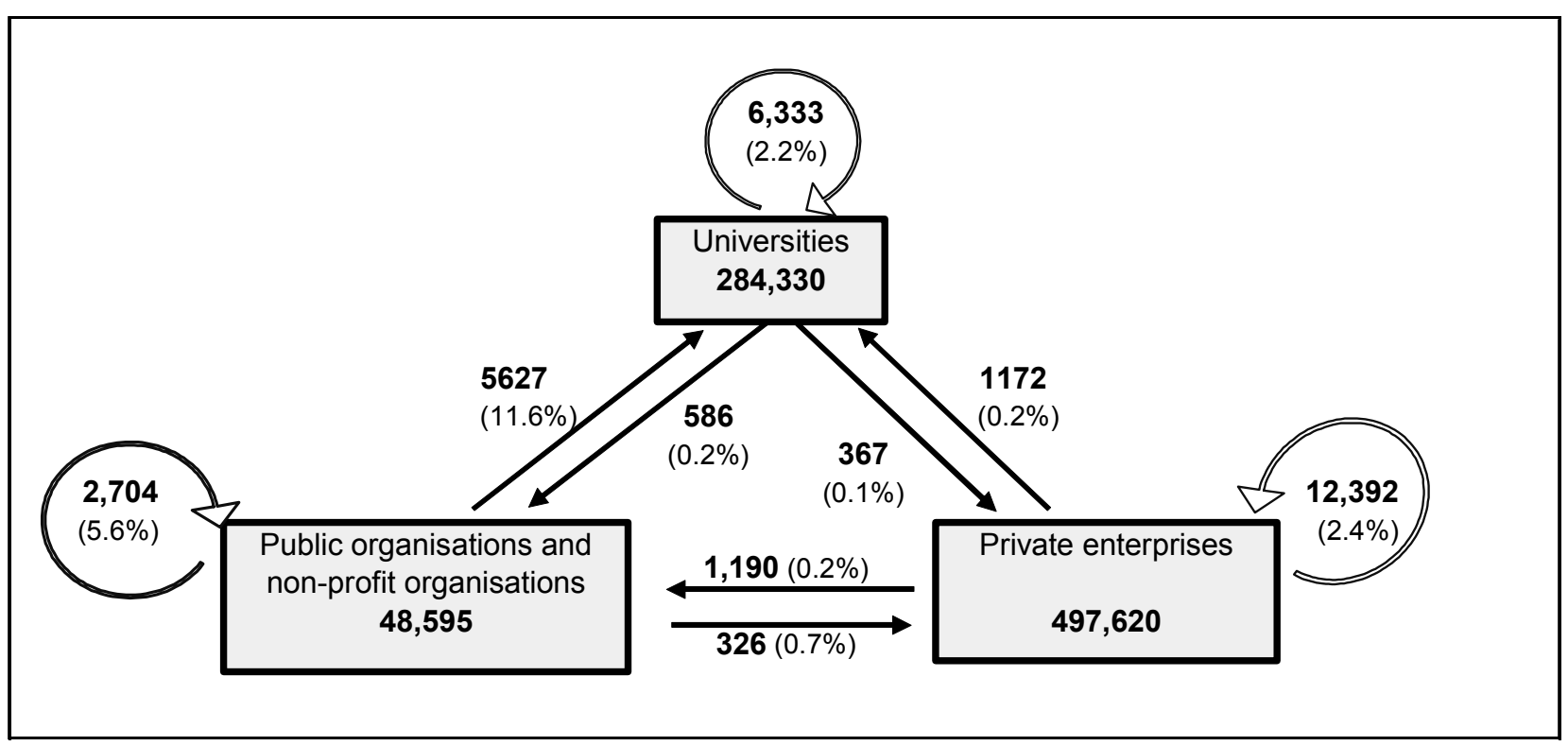

1. Including liberal arts and social studies, and including post-doctoral students. Figures in parentheses show the proportion of researchers in each sector that changed positions in 2003.

Source: National Institute for Scientific and Technological Policy (NISTEP) and Mitsubishi Research Institute (2005). 


\section{A low degree of openness to international trade and investment}

10. Innovation performance is also related to the degree of openness to knowledge and ideas generated abroad. The penetration of foreign affiliates in both manufacturing and services is the lowest in the OECD area (see Chapter 6 of the 2006 OECD Economic Survey of Japan). ${ }^{15}$ In addition, Japan, together with Korea, has the lowest share of highly skilled foreign workers in its labour force. Although Japan encourages foreign researchers and other highly skilled workers to work and study in Japan, their access to the labour market is restricted as they must have studied at the university level the subject relevant to the job concerned. Not surprisingly, Japan is ranked at the bottom in many of the indicators on international linkages in R\&D. For example, it is the least active country in international co-operation in R\&D activities in the OECD area (Figure 2, line 12) and the share of foreign ownership of domestic patents is extremely low (line 10). Japanese firms that have established overseas research centres and R\&D alliances with foreign firms have achieved better innovation performances (OECD, 2003b).

\section{Problems in the education system undermine the science base}

11. Scientific research is a major source of technological progress, indicating the importance of education for both the creation and implementation of innovation. Despite high graduation rates for both upper secondary and tertiary education in Japan, there are a number of weaknesses. Japan ranked $22^{\text {nd }}$ in the OECD area in 2002 in the number of doctoral graduates as a share of the relevant age cohort (OECD, 2005a). The share of new students in science, engineering and agriculture courses at the university level declined from 26\% in 1995 to $23 \%$ in 2004 (Cabinet Office, 2005a). The share of women in science and technology is also low. Indeed, the proportion of women among students who completed undergraduate, master and doctoral coursework in engineering (10\%) was the lowest in the OECD area in 2002, while in the case of science degrees, it was the second lowest (39\%). Although Japan's high level of basic education contributed to faster growth during the period of mass production and catching-up, the lack of diversity and the declining level of basic education, as suggested by international test results (see below), may act as a drag on the diffusion of innovation.

\section{The lack of a risk-taking culture that encourages entrepreneurship}

12. A market environment that is conducive to risk-taking enhances entrepreneurship as well as the capacity to innovate. However, venture capital investment and entrepreneurship are exceptionally weak in Japan. Venture capital investment as a share of GDP is the second lowest among OECD countries (Figure 6). Moreover, the share of Japanese venture capital invested in high-technology sectors, such as communications, IT and biotechnology, is the third lowest among OECD countries, and about half of the OECD average (OECD, 2005e). Business start-ups are also less frequent in Japan, accounting for $4 \%$ of firms compared with around $10 \%$ in Europe and $14.3 \%$ in the United States. ${ }^{16}$ Not surprisingly, Japan is ranked at the bottom of the International Institute for Management Development's (IMD) rankings on entrepreneurship.

15. In 2002, the share of foreign-controlled affiliates in total manufacturing turnover ranged from $75 \%$ in Ireland to less than 3\% in Japan. In services, the share of foreign affiliates ranged from almost $40 \%$ in Ireland to less than $1 \%$ in Japan. Foreign affiliates also made a negligible contribution to labour productivity growth in Japan's manufacturing sector, compared with almost a quarter in the United States.

16. Ando and Motohashi (2002) based on 1996-99 for Japan and 1997 for the United States and Europe. 


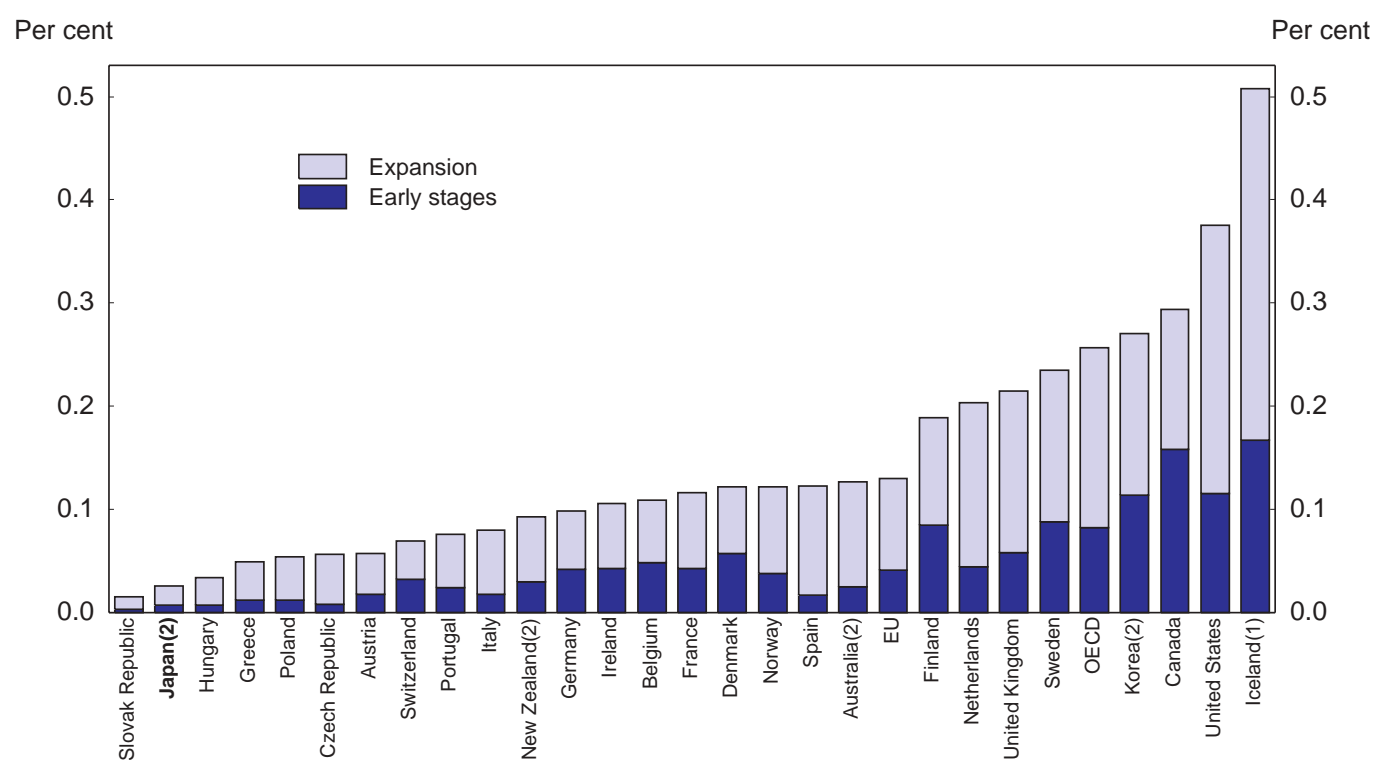

1. Data from $2000-02$.

2. Data from 1998-2001.

Source: OECD, OECD Science, Technology and Industry Scoreboard 2005.

\section{Problems in the regulatory framework slow innovation}

13. Another important factor is that framework conditions - which include product market competition and the financial system - have failed to support the transition of the Japanese innovation system to the global standard. An econometric study of change in business R\&D intensity found that Japan was one of four OECD countries in which the framework conditions reduced business-sector R\&D intensity during the 1990s (Jaumotte and Pain, 2005b). Moreover, the negative impact of framework conditions was by far the largest. One aspect of framework conditions is product market regulation, where Japan ranked $11^{\text {th }}$ in the OECD area in 2003, well behind the front-runners. Moreover, an indicator of regulatory reform in seven non-manufacturing industries placed Japan in the middle of the six largest OECD economies (Figure 7). Nevertheless, productivity growth has accelerated in some sectors that experienced relatively rapid progress in regulatory reform, suggesting that appropriately designed framework conditions can enhance innovation outcomes. ${ }^{17}$

14. Slow progress in reforming regulations in the service sector has hindered productivity growth. Indeed, average labour productivity in services fell from 88\% of the US average in 1993 to $84 \%$ in 2003, despite the high and rising level of productivity in Japan's finance, insurance, real estate and business services, which is above US levels (Figure 8). Excluding those industries, labour productivity in the service sector declined from $85 \%$ to $78 \%$ of the US level over the same period. Moreover, knowledge-intensive industries (post and telecommunications, finance, insurance and business activities) account for only $16.5 \%$ of value added, well below the United Kingdom at $22.5 \%$ and the United States at $24.3 \%$. In addition, the share of services in business R\&D in Japan is the lowest in the OECD area (Figure 9).

17. The telecommunications sector in Japan raised its productivity during the 1990s, albeit at a slower pace compared with that sector in the United States, and in some sectors, such as mobile commerce, they are leading the OECD. However, the electricity and air transport industries recorded declines in productivity during the 1990s in contrast to rising productivity in the United States (Ando and Motohashi, 2002). 
Figure 7. Regulatory conditions in seven non-manufacturing sectors Zero means least restrictive ${ }^{(1)}$

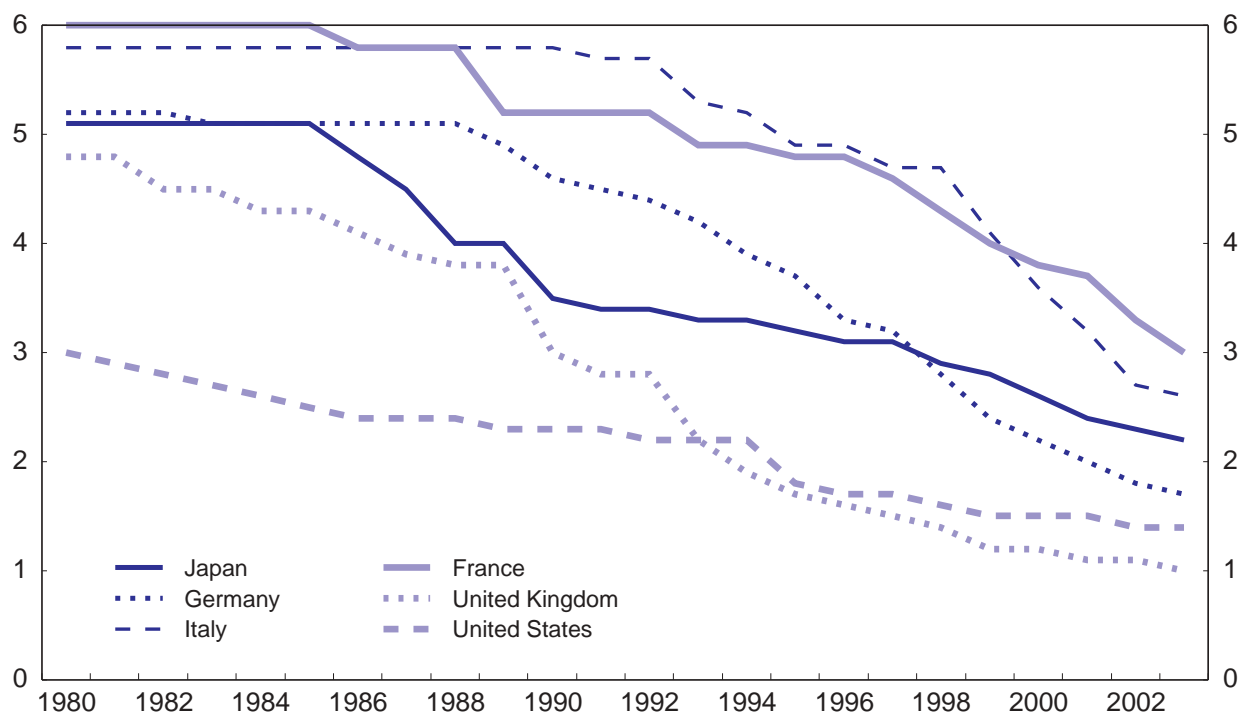

1. The regulatory indicator is calculated as the simple average of the seven sectoral indicators. The sectors are telecommmunications, electricity, gas, post, road, rail and air passenger transport. Scores range between 0 and 6.

Source: OECD Product Market Regulation Indicators Database.

Figure 8. Comparison of productivity in the Japanese service sector US = 100 using PPP exchange rates

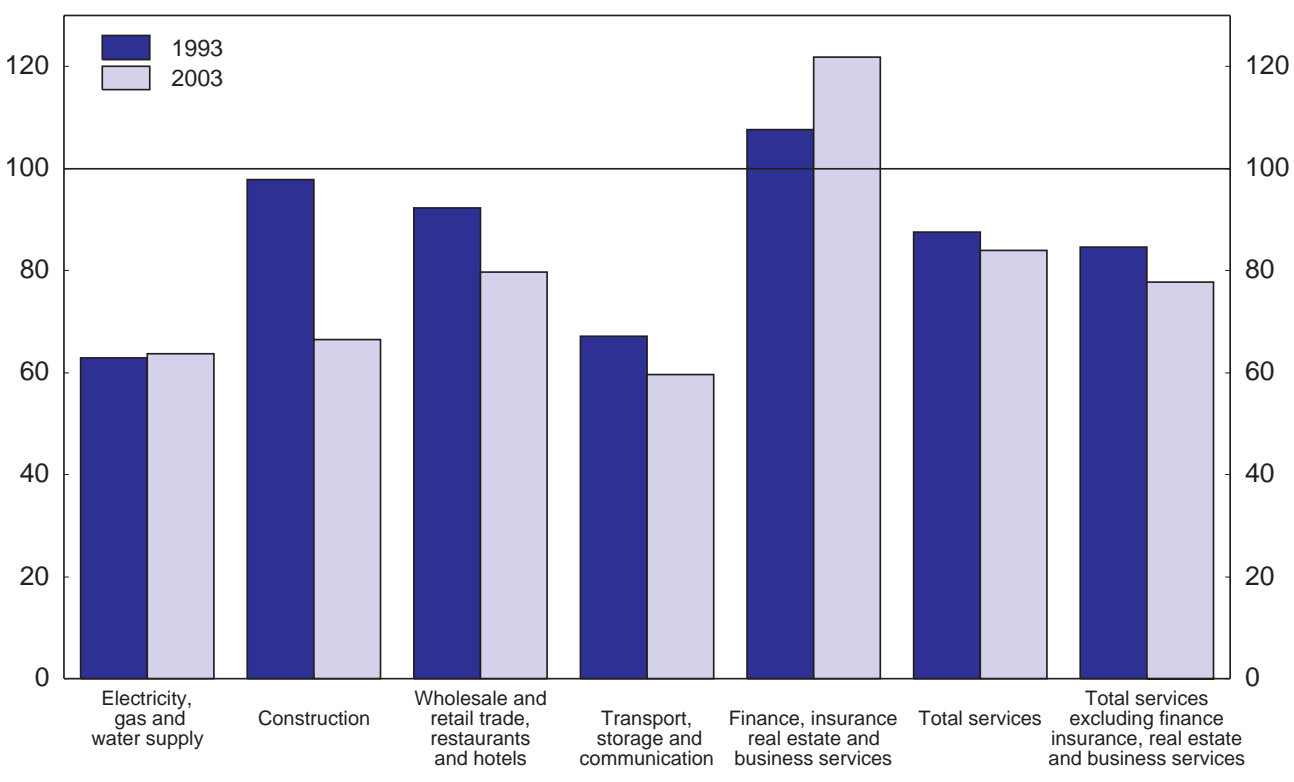

Source: OECD STAN database and OECD Economic Outlook 79 database. 
Figure 9. Share of the service sector in business R\&D $2003^{(1)}$

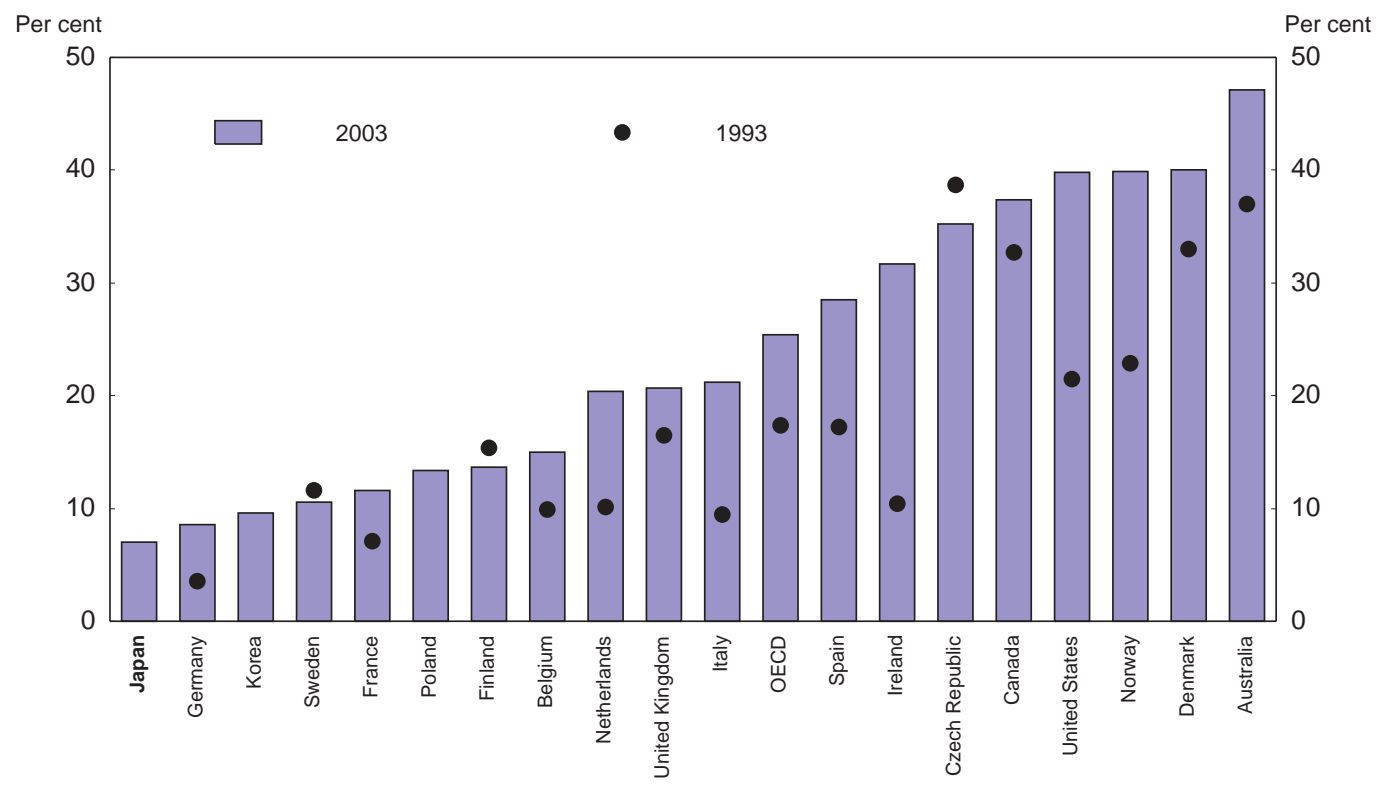

1. Or most recent data available. See the source for more precise information. Source: OECD, OECD Science, Technology and Industry Scoreboard 2005.

\section{Recent government initiatives to strengthen the national innovation system}

15. The weaknesses outlined above have limited the positive impact from the expansion in R\&D activities during the 1990s. Consequently, increased innovation inputs have failed to offset the deceleration in productivity growth recorded during the decade of depressed economic conditions. The government promotes innovation through its spending on $\mathrm{R} \& \mathrm{D}$, which accounts for a quarter of total R\&D outlays, and by policies influencing private-sector innovation activity. This section discusses the Council for Science and Technology Policy and the New Industry Promotion Strategy.

\section{The Council for Science and Technology Policy and the third Basic Plan}

16. The Council for Science and Technology Policy (CSTP) was created in 2001 to formulate and co-ordinate government policies in this area. The CSTP is chaired by the prime minister ${ }^{18}$ and supported by a secretariat established in the Cabinet Office. ${ }^{19}$ The Council's main activities are to formulate the Basic

18. In addition to the prime minister, the council is composed of six other ministers (including the Minister for Science and Technology Policy), seven private-sector experts and the president of the Science Council of Japan (an independent association of academic experts). Its work is carried out in monthly meetings chaired by the prime minister, as well as seven expert panels covering: i) basic policy; ii) promotion strategy for priority areas; iii) evaluation; $i v$ ) science and technology system reform; v) bioethics; vi) space development and utilisation; and vii) management of intellectual property. The CSTP has produced a wide range of reports through more than 50 plenary meetings and 230 expert panel meetings since 2001.

19. The 127-person staff (as of November 2005) is composed of 82 officials from various ministries (primarily the Ministry of Education, Culture, Sports, Science and Technology (MEXT) and the Ministry of Economy, Trade and Industry), 22 from public research institutes and universities and 23 from the private sector. 
Plan for Science and Technology Policy (see below) and to evaluate the innovation policies of each ministry, mainly by assessing their budget proposals. New projects with a budget of over 100 million yen (\$0.8 million) and on-going projects of over 1 billion yen ( $\$ 8.5$ million) are classified into four groups according to the priorities set by the Council (the so-called "SABC" system, with S reserved for the highest priority projects and C for the lowest). In FY 2006, 900 billion yen ( $\$ 7.6$ billion) - about a quarter of total science and technology budget requests - went through such evaluations before the budget was finalised. The Council has had some impact in changing the composition of science and technology spending; the budget for projects categorised as S, A, B and C changed by $+16 \%,+12 \%,-3 \%$ and $-30 \%$, respectively, in FY 2005 compared with FY 2004. However, the change in the allocation of the science and technology budget across ministries has been small at less than 1 percentage point between FY 2001 and FY 2004 (Table 1).

17. Despite the important role of science and technology policy in enhancing economic growth, the CSTP's activity was confined in the past to purely scientific issues. Relatively little attention has been paid to the economic impact of innovation and the framework conditions needed to support such activities, particularly in the service sector. For example, the expert panels established thus far have given little emphasis to the overall impact of innovation on economic growth or the relationship with economic policies, reflecting in part the very small number of economists participating in the CSTP's panels. Furthermore, the CSTP should have more authority to improve framework conditions for innovation. For example, the Council's specific recommendations to improve the R\&D system, in part through measures to increase R\&D-based venture companies and the mobility of researchers, have not been fully implemented by the ministries. However, more recently, the CSTP appears to play a more active role in relation to economic policy. For example, in its "Comprehensive Strategy for Creating Innovation" (published in June 2006), the CSTP made specific recommendations to improve the R\&D system, including measures to encourage closer industry-academia co-operation.

18. The government has implemented two Science and Technology Basic Plans, covering the periods of 1996-2001 and 2001-06. The second Plan placed more emphasis on basic research, greater co-operation among industry, academia and government and systemic reforms, such as expanding the competitive research grant system. It also identified four priority areas: i) life science; ii) information technology; iii) environment; and iv) nanotechnology and materials. Although the target for total government (including local government) expenditure on science and technology policy was increased from a total of 17 trillion yen during the first Plan to 24 trillion yen, weaker-than-expected economic conditions limited outlays to 21 trillion yen. Nevertheless, public R\&D outlays rose from $0.7 \%$ of GDP during the first Plan to $0.8 \%$ in the second. Other numerical targets such as " 30 Nobel laureates in 50 years" were also included in the second Plan. The share of the budget allocated to the four priority areas increased from $38 \%$ to $46 \%$ and the share of competitive grants rose from 8\% to 13\% between FY 2001 and FY 2005.

19. The government announced in March 2006 the third Science and Technology Basic Plan for FY 2006-2010, which was formulated by the CSTP (see Box 3). The Plan emphasises the importance of creating a knowledge-based economy in the context of intensifying worldwide competition, particularly with Asian countries including China and Korea. It includes a number of positive systemic reforms, such as encouraging human resource development, enhancing the mobility of researchers, expanding the role of universities, increasing competition in research funding and strengthening international linkages. 
ECO/WKP(2006)55

Table 1. National science and technology research system

\begin{tabular}{|c|c|c|c|c|c|}
\hline & $\begin{array}{c}\text { Number of } \\
\text { national } \\
\text { research } \\
\text { institutes }\end{array}$ & $\begin{array}{c}\begin{array}{c}\text { Number of } \\
\text { independent } \\
\text { administrative } \\
\text { agencies }\end{array} \\
\text { FY } 2005\end{array}$ & \multicolumn{3}{|c|}{ Science and technology-related budget in FY 2004} \\
\hline Diet & 0 & 0 & 1.0 & 0.0 & 0.0 \\
\hline Cabinet Office & 1 & 0 & 10.0 & 0.3 & 0.1 \\
\hline National Policy Agency & 1 & 0 & 2.2 & 0.1 & 0.0 \\
\hline Japan Defense Agency & 1 & 0 & 185.5 & 5.1 & 0.8 \\
\hline Ministry of Internal Affairs and Communications & 0 & 3 & 80.1 & 2.2 & -0.2 \\
\hline Ministry of Justice & 1 & 0 & 2.2 & 0.1 & 0.0 \\
\hline Ministry of Foreign Affairs & 0 & 0 & 10.3 & 0.3 & 0.0 \\
\hline Ministry of Finance & 1 & 1 & 1.5 & 0.0 & -0.1 \\
\hline $\begin{array}{l}\text { Ministry of Education, Culture, Sports, Science and Technology } \\
\text { (88 national university corporations) }\end{array}$ & 4 & 15 & $\begin{array}{r}2284.0^{1} \\
(1040.6)\end{array}$ & 63.3 & -0.5 \\
\hline Ministry of Health, Labour and Welfare & 9 & 5 & 129.0 & 3.6 & 0.0 \\
\hline Ministry of Economy, Trade and Industry & 0 & 9 & 605.3 & 16.8 & 0.6 \\
\hline Ministry of Land, Infrastructure and Transport & 5 & 9 & 83.7 & 2.3 & 0.0 \\
\hline \multirow[t]{2}{*}{ Ministry of the Environment } & 2 & 1 & 31.2 & 0.9 & 0.0 \\
\hline & 26 & 51 & 3608.4 & 100.0 & 0.0 \\
\hline
\end{tabular}

1. Including the budget of the national university corporations.

Source: MEXT, 2002 and 2005a. 
20. Despite many positive elements, there is still much room for improvement. First, there should be more focus on increasing efficiency in R\&D spending rather than meeting a specific spending level, which risks encouraging wasteful investment. Past experience shows that expenditure targets for public works, such as roads and airports, led to inefficient investment and contributed to the rapid rise in government debt. Moreover, the extent of the planned increase, from the 21 trillion yen spent in the second Plan to 25 trillion yen in the third, is considerable in the context of the spending restraint needed to reduce the budget deficit. As noted above, public R\&D spending as a share of GDP in Japan is already close to the OECD average (Figure 2), while there is considerable scope for improving the efficiency of these outlays. There is a risk that a generous medium-term spending target could encourage inefficient spending. As with all government spending, there is a need to ensure the efficiency of R\&D investment. Second, the third Plan allocates about half of its resources to a limited number of priority areas. The approach of allocating $R \& D$ resources to specific areas is also used in many other countries (OECD, 2006b). The government's objective is to influence the research activities of universities and public research institutes, which are increasingly independent. However, giving undue emphasis to priority areas could lead to government failure and distortions. Moreover, focusing on key products also poses a risk of a deterioration in the terms of trade (through falling export prices) as other countries also increase production in these areas. Japan has experienced significant terms of trade losses in recent years due to its high dependence on ICT, suggesting that there are gains to a diversified approach to R\&D (Figure 10). Government R\&D spending should focus more on areas with large positive externalities. Third, in the allocation of public R\&D funds, greater importance should be attached to the non-manufacturing sector, given that the service sector accounts for about $60 \%$ of GDP. Fourth, although the Plan emphasises the importance of improving framework conditions in order to encourage innovation and calls for greater interaction between science and technology policies and economic policies, the specific recommendations are still confined to the area of science and technology. ${ }^{20}$ More recently, however, as mentioned above, efforts have been made to improve the R\&D system through better framework conditions.

Figure 10. Impact of the terms of trade on income

Cumulative gap between command GDP and standard GDP between 1990 and $2004^{(1)}$

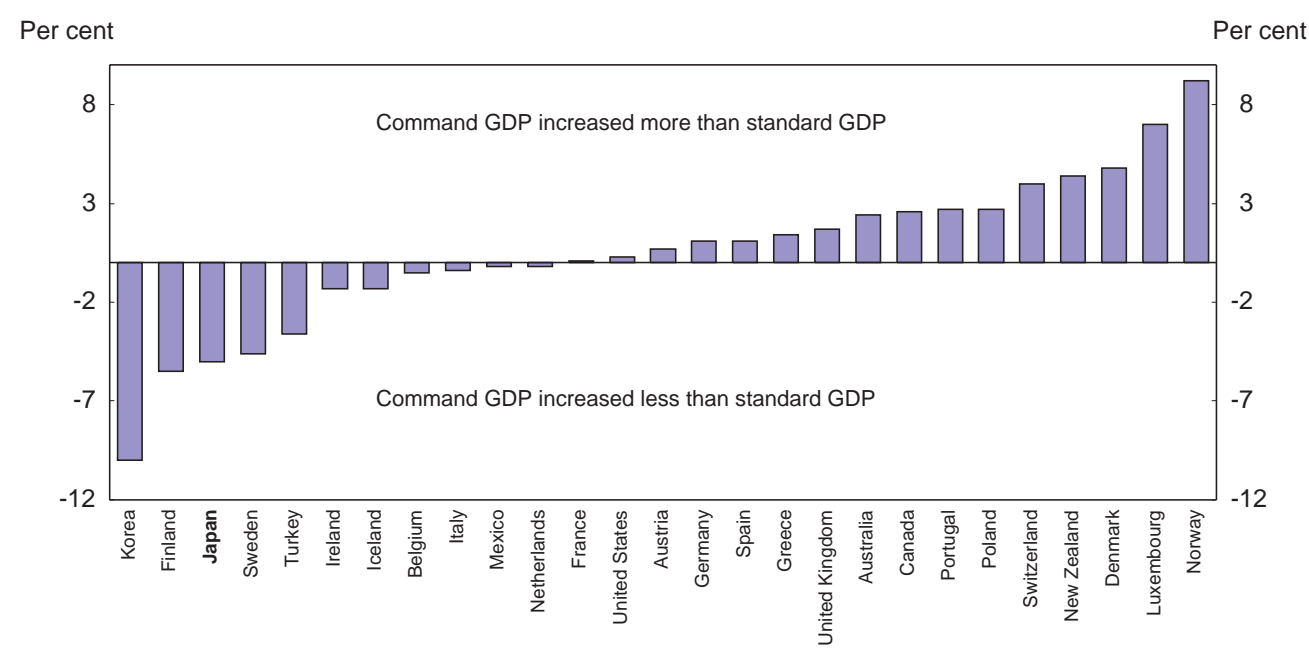

1. Command GDP adjusts GDP for the terms of trade effect by deflating exports by the import price deflator: Command GDP = TDDV + XGSV * (PXGS/PMGS) - MGSV where TDDV is real domestic demand, XGSV and MGSV are exports and imports in volume terms, and PXGS and PMGS are the export and import deflators. Source: OECD, Economic Outlook 79 database.

20. This partly reflects the traditional segmentation of "liberal arts" and "science" people, based on their university degrees, which has a crucial impact on salaries and promotions in both public and private-sector organisations. The link between science and technology and economic policy tends to be weakened due to insufficient interaction between the two groups. 
ECO/WKP(2006)55

\section{Box 3. The third Science and Technology Basic Plan}

\section{Basic ideas}

- $\quad$ Promote science and technology that is supported by the public and provides benefits to society.

- Foster human resource development and a competitive research environment

- Aim at six goals: i) realise great discoveries and inventions; ii) break through science and technology frontiers; iii) balance environmental and economic concerns; iv) enhance innovation by establishing appropriate economic conditions; v) promote a healthy and active life for all citizens; and vi) create the safest nation in the world.

- Increase total public R\&D spending to 25 trillion yen over five years (1\% of GDP on an annual basis, well above the average of around $0.7 \%$ during 2001-03), while taking the fiscal situation into account in setting annual budgets.

\section{Strategic prioritisation}

- The prioritisation efforts made during the second Basic Plan are to be re-enforced by strengthening the selection and concentration of investment in the following key areas:

i) Basic research, including that in non-priority areas;

ii) The four priority areas already identified in the second Plan - life science, information technology, environment, and nanotechnology and materials - which address key national challenges;

iii) Four promotion areas - energy, manufacturing, social infrastructure and the frontiers of outer space and oceans - which are fundamental to Japan.

- $\quad$ The CSTP will formulate a strategy for each of the priority and promotion areas based on criteria such as scientific research, economic and social impact, international comparisons and investment risks.

- The CSTP has chosen "Strategic Priority Science and Technologies (SPSTs)", which will receive largescale investment during the third Basic Plan.

- Among the SPSTs, the CSTP identified "National Key Technologies", such as next-generation super computers and space transportation systems, which will be promoted by large-scale investments.

\section{Systemic reform of science and technology}

- Promote human resource development through fair and transparent evaluation and recruitment of researchers. Provide more opportunities, through financial aid and other support, and improved working conditions for researchers who are young, female, foreign or elderly. Boost the share of female researchers from $11 \%$ to $25 \%$.

- Enhance the mobility of researchers by expanding the use of fixed-term contracts and performance evaluation at universities and public research institutes. Require young researchers to change their organisational affiliation at least once after graduation before obtaining a permanent position. Publish information on the share of researchers who work at the same university from which they graduated.

- Strengthen the role of universities and graduate schools in human resource development, in part through the establishment of long-term internship programmes in co-operation with industry. Increase support for upper secondary schools that put priority on science and mathematics.

- Further expand the use of competitive funding for research, based on improved evaluation of such programmes. Substantially raise the share of private sector-funded research carried out in universities by strengthening ties between industry, university and government through greater support for technology licensing organisations (TLOs), university start-ups and other measures.

- Strengthen international linkages through greater participation in the setting of international standards, such as by the International Organisation for Standardisation. Extend the length of time that foreign 
Role of the CSTP

- Re-enforce the CSTP's co-ordinating function through closer links with other government councils. Achieve stricter prioritisation of outlays based on improved evaluation methods. Accelerate the reform of independent administrative agencies, including universities, by closer monitoring of their activities.

- $\quad$ Promote the development of science and technology by actively participating in the formation of policies in other areas.

\section{The New Industry Promotion Strategy}

21. The Ministry of Economy, Trade and Industry (METI), which accounts for one-sixth of public R\&D spending, is also promoting innovation, mainly in the industrial sector. In 2004, the Ministry compiled the "New Industry Promotion Strategy", which specifies seven priority areas - fuel cells, digital consumer electronics, robots, software, health/welfare, environment/energy and professional services - to support the Japanese economy over the next 20 to 30 years. After consultation with specialists and the business sector, the government selected these industries because of their broad-based impact, which extends to raw materials and finished products, small and medium-sized enterprises (SMEs) and large corporations, and rural areas and large cities. ${ }^{21}$ In addition, these industries were chosen because market forces alone were judged to be insufficient to ensure development and joint efforts by the government and the private sector are thought to be necessary. Policies to promote these areas include increased R\&D spending, strengthened competition (healthcare) and the establishment of regulatory frameworks (robots). The report focuses on the traditional innovation process based on interaction between the existing network of parts and material industries in Japan, and calls for further development of such networks. Finally, the report presents "technology roadmaps" for 20 areas for the period 2005 to 2030 . The importance of global networks is discussed in the context of coping with module-based production, which is assumed to dominate the production system in the later stage of technology development.

22. The "New Industry Promotion Strategy" raises a number of concerns with respect to its impact on innovation. First, as in the third Science and Technology Basic Plan, the choice of seven priority sectors raises the risk of government failure and distortions. To the extent that the government focuses on regulatory reform to promote competition, the impact would certainly be positive. However, such efforts should be extended more broadly. Second, given the rapid pace of technological change, roadmaps covering up to 25 years are unlikely to be very useful. Third, while it is true that innovation is often encouraged by the geographical concentration of various actors, the government should avoid mixing national innovation policies with measures aimed at promoting balanced regional development. Fourth, the focus on parts and materials suppliers for domestic industries is less appropriate in a globalised economy.

\section{Policies to upgrade the national innovation system}

23. A comprehensive approach is needed to transform the Japanese innovation system and bring it into line with best practices in the OECD area. Given that the core of the problem lies in the relatively closed and self-contained innovation system and the weak service sector, framework policies that open up research systems and improve the allocation of resources should be placed at the centre of reform. For

21. In addition, METI is promoting "Knowledge Cluster Projects" to promote development in 19 districts. Meanwhile, MEXT's “Intellectual Cluster Project" is being implemented in 15 regions. 
measures to accelerate the integration of Japan in the global economy, see Chapter 6 of the 2006 OECD Economic Survey of Japan.

\section{Framework policies to support innovation activities}

24. This section discusses four major policy priorities: $i)$ strengthening venture capital investment; ii) enhancing the mobility of workers; iii) upgrading product market regulation and competition policy; and iv) improving the system of intellectual property rights.

\section{Strengthening venture capital investment}

25. The venture business sector plays an important and growing role in advancing innovation in many OECD countries. However, in Japan, venture capital investment has been stagnant during the past decade at a very low level of around $0.05 \%$ of GDP, and the outstanding amount decreased from a peak of 1 trillion yen ( $0.2 \%$ of GDP) in 2002 to 860 billion yen in 2005 (Venture Enterprise Center, 2005). The low level is a result of a number of factors. First, households' appetite for risk is low, as indicated by the fact that the share of their assets in savings accounts is more than double that in other major countries, while the share in risky assets is considerably lower. Second, companies depend heavily on indirect financing. Third, the share of investment by pension funds, which make decisions from a longer-term perspective, is only $4 \%$ of total investment, compared with $40 \%$ in the United States and the United Kingdom (Figure 11). Such a low share reflects government regulations on pension fund portfolios, including the so-called "5-3-3-2" rule that was in force until 1997. ${ }^{22}$ Consequently, pension fund portfolio did not change much until the end of the 1990s. Fourth, the role of universities in the venture sector has been limited, as discussed below.

26. In addition, many venture capital funds are subsidiaries of financial institutions, which lack expertise in monitoring and supporting venture companies and are less eager to take risks (Takahashi, 2006 and EPA, 1999). This limits the role of venture business in cutting-edge technology. Indeed, venture investment in high-technology areas, including ICT and health/biotechnology, is only $23 \%$ of the total, compared with an OECD average of nearly $50 \%$. In contrast, traditional industries in the manufacturing sector attracted more venture capital investment (OECD, 2005j and JASMEC, 2002). In addition, venture investment in Japan is concentrated in later-stage technology, although the share of early-stage companies has increased somewhat in recent years. Moreover, Japanese venture capitalists are relatively less involved in the management of the companies in which they invest (JASMEC, 2002 and EPA, 1999). This reflects the fact that the average size of venture investments in Japan is only about $3 \%$ of that in the United States and about one-third of that in European countries.

27. Some reforms have been introduced in recent years to encourage venture capital investment. First, the financing of venture companies has been facilitated by the creation of second-tier stock markets, such as MOTHERS in Tokyo and HERCULES in Osaka, and the relaxation of listing requirements in JASDAQ. There have been more than 100 initial public offerings in these three markets each year since 2000, helping to boost their total market capitalisation from 8 trillion yen in 2002 to 20 trillion yen (4\% of GDP) in 2005. Second, the incorporation of universities in 2004 is encouraging university-business start-

22. The "5-3-3-2" regulation required pension funds to diversify their assets, by holding: i) more than 50\% in guaranteed assets such as government bonds; ii) less than $30 \%$ in stocks; iii) less than $30 \%$ in foreign assets; and iv) less than $20 \%$ in real estate. 
ups. Third, preferential tax treatment for venture capital investment has been expanded ${ }^{23}$ while the minimum capital requirement for start-ups has been lowered.

\section{Figure 11. Sources of venture capital funds} $1999-2001^{(1)}$

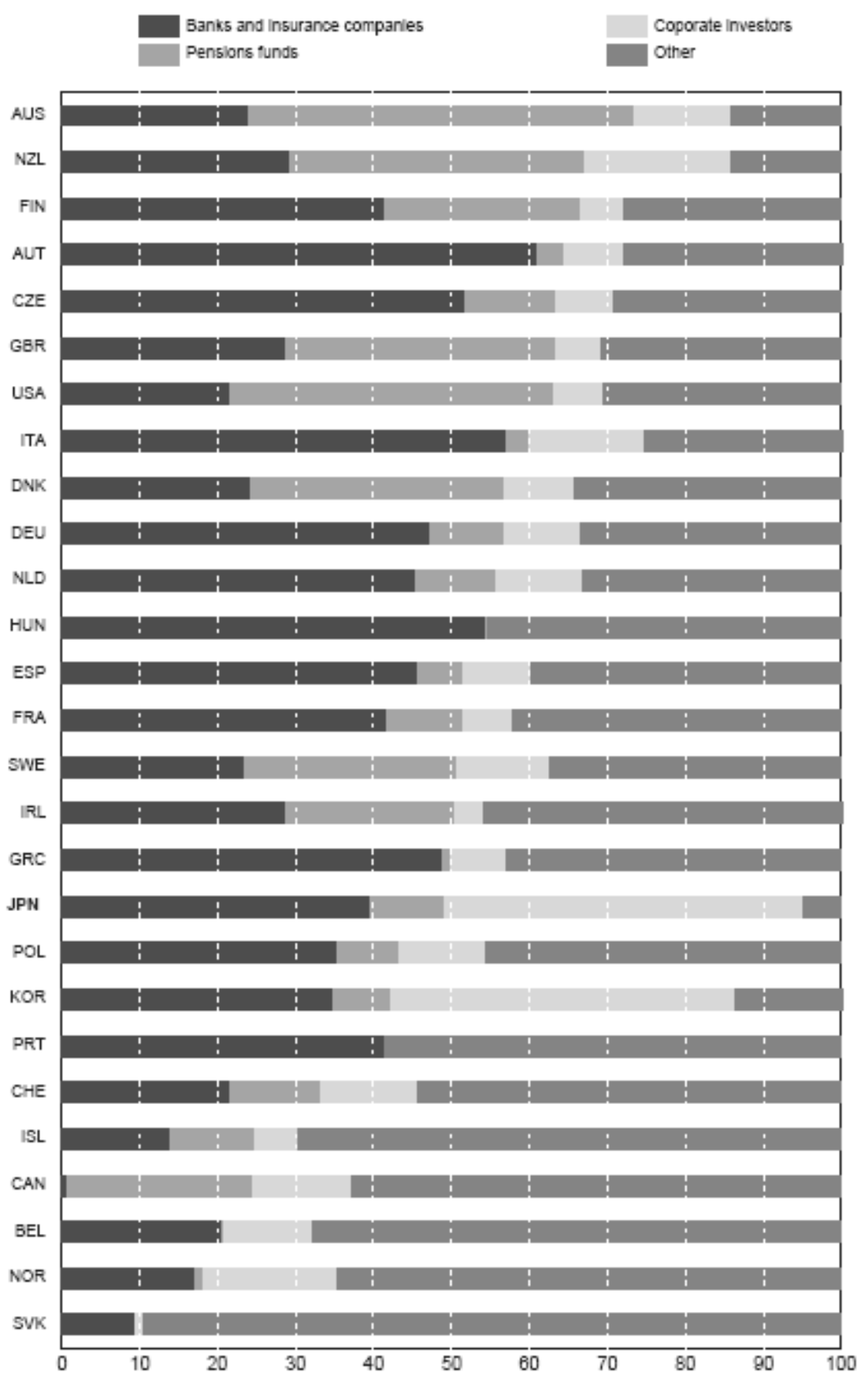

1. Countries are ranked according to the sum of banks, insurance companies and pension funds. Source: OECD (2006b), Economic Policy Reforms: Going for Growth.

23. In particular, the "Angel Tax System" provides a 50\% tax cut for capital gains from the sales of venture companies' shares by individual investors under certain circumstances. 
28. However, a broad-based programme is needed to transform business practices to encourage risktaking based on new technology. The traditional system of extensive indirect financing, centred on the main bank and corporate groups (keiretsu) with large cross share-holding, has encouraged long-term investment but not risk-taking. In addition, the increase in the share of loans by public financial institutions may have prevented the exit of less competitive firms while hindering the development of the capital market to supply risk money. The government should thus scale back lending by public financial institutions and follow-through on the privatisation of Japan Post (see the 2005 OECD Economic Survey of Japan). Indeed, lending by public financial institutions has risen from less than $15 \%$ of total bank loans at the beginning of the 1990 s to around $20 \%$ in recent years. In addition, the government should encourage venture investment by reducing capital gains taxes, which are relatively high for individuals and companies in Japan compared with other OECD countries (OECD, 2006b). This has reduced both the willingness of individuals to commit savings to venture funds and the incentive of entrepreneurial firms to engage in high-risk activity. As for the direct role of the government, programmes to promote venture investment should focus on leveraging and diversifying private sources of venture capital and moving small firms away from dependence on public debt guarantees and public finance (OECD, 2006b). In addition, universities should play a larger role in enhancing venture investment though a better match of their R\&D base and business needs (see below).

\section{Policies to enhance mobility of researchers and workers}

29. A lack of mobility of researchers is a key weakness of the innovation system in Japan, in part because it limits the scope of interaction between research institutes in the government, business and higher education sectors. According to a government survey, research managers replied that greater mobility of researchers would create a number of problems, including the loss of technology and competent personnel, and difficulties in accumulating know-how and making long-term plans (Figure 12). In practice, researchers are effectively tied to their institutes (Figure 5) through a number of employment practices. Over $40 \%$ of researchers responded that retirement allowances were the most important factor discouraging a move to a new organisation. Although there is no legal requirement to pay retirement allowances, almost all companies pay a lump-sum benefit that increases progressively according to the length of employment. ${ }^{24}$ In addition, pension schemes discourage mobility due to the lack of portability and the length of time required to become eligible to receive payments. ${ }^{25}$ Disadvantages in promotion and income were relatively important for private-sector researchers, suggesting that tenure-based pay and promotion are still dominant.

30. The government is taking measures to increase the mobility of researchers by: $i$ ) restructuring the national pension system to increase portability; ii) advising institutions to establish fair and transparent human resource management and evaluation systems; and iii) providing information on job opportunities. The proportion of national research institutes using external vacancy notes has been increased from $69 \%$ in 2001 to $81 \%$ in 2003 . However, the share remains significantly lower at universities, leading to a problem of "inbreeding". In order to significantly enhance the mobility of researchers, the government should

24. More than $95 \%$ of companies with over 100 employees pay a lump-sum retirement allowance, and $63 \%$ of them adopted a tenure-based calculation system (Ministry of Internal Affairs and Communications, 2001). In the case of mandatory retirement, the indexed amount of allowance was 41 for 10 years of tenure, 100 for 20 years and 212 for 40 years. It was even more progressive for the case of voluntary retirement ( 34 for 10 years, 100 for 20 years and 238 for 40 years).

25. The introduction of a defined contribution system in 2001 improved the situation somewhat, although only $2 \%$ of employees are currently covered by such a system and its portability is limited. 
encourage the use of fixed-term contracts at universities and government research institutes ${ }^{26}$ and the introduction of a performance-based pay system in the private sector.

\section{Figure 12. Reasons for low mobility of researchers Per cent}

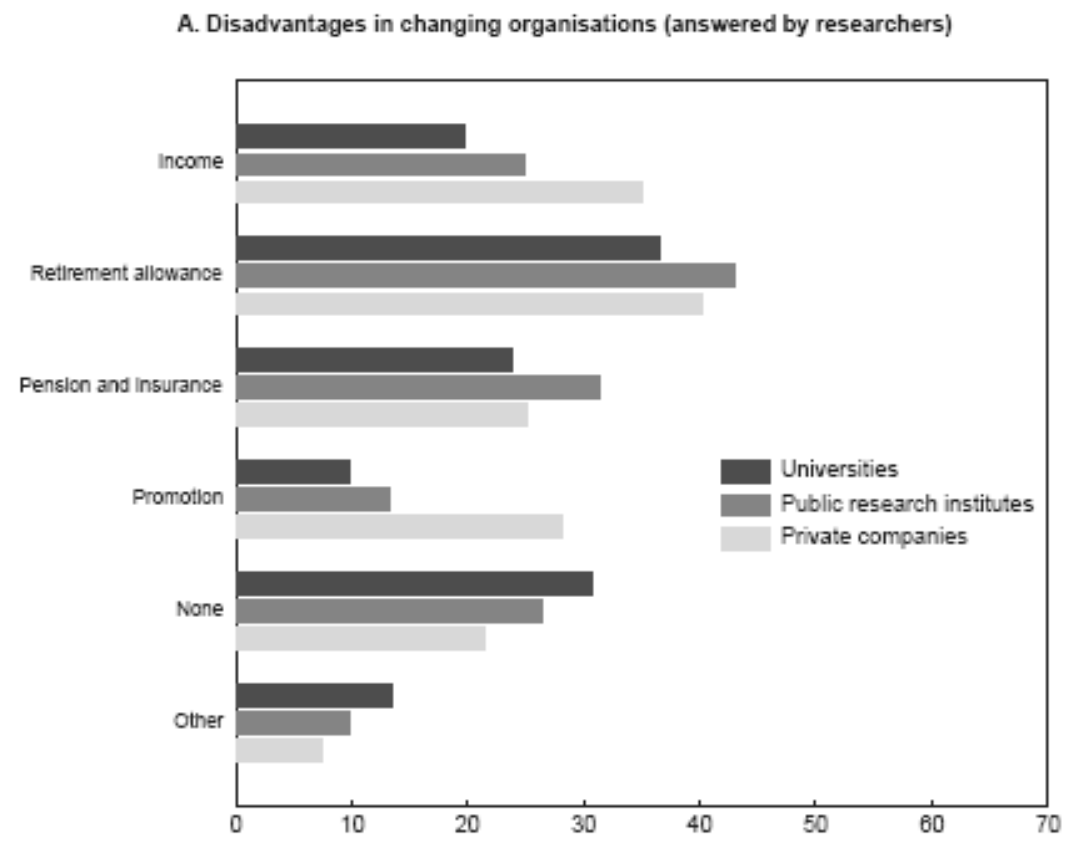

B. Disadvantages of higher mobility of workers (answered by research managers)

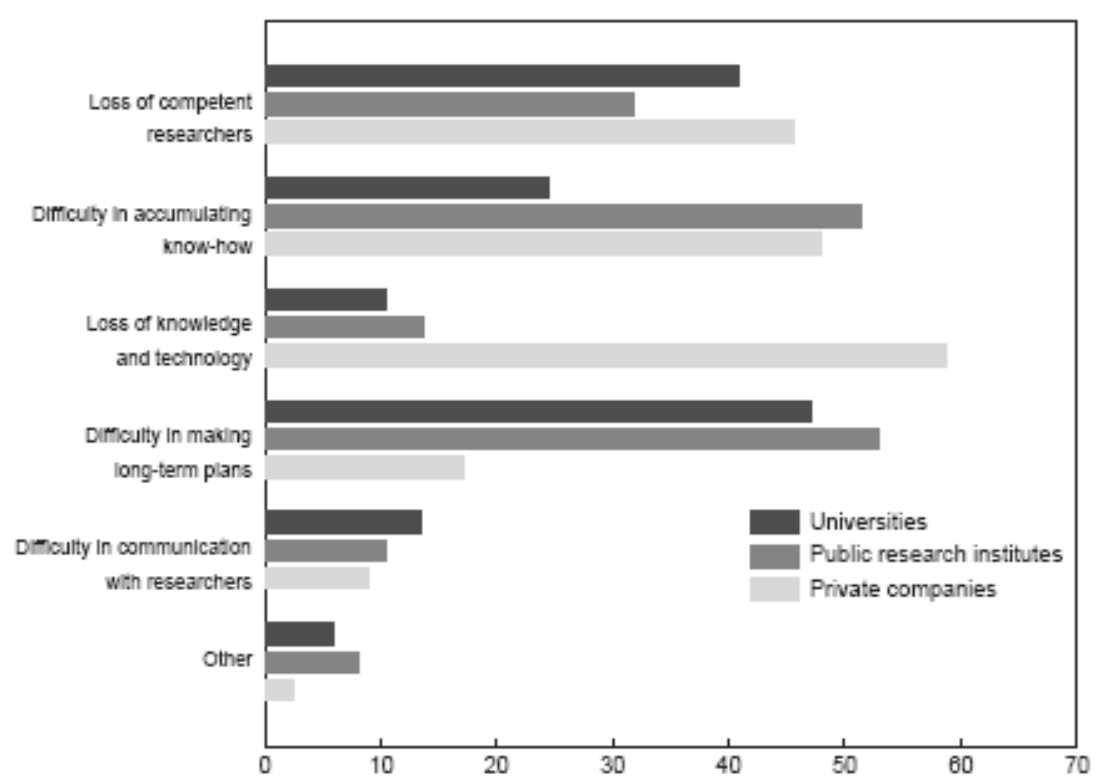

Source: National Institute for Scientific and Technological Policy (NISTEP) and Mitsubishi Research Institute (2005).

26. The share of researchers under a fixed-term contract was only $3.4 \%$ for universities in 2002 and $6.0 \%$ for government research institutes in 2004. 
31. In addition to the mobility of researchers, strict employment protection weakens incentives to innovate as the full benefit of cost-reducing technology often requires staff reductions or changes in the skill-mix of employees. ${ }^{27}$ Employment protection for regular workers in Japan is above the median of OECD countries (see Chapter of the 2006 OECD Economic Survey of Japan). Labour practices that limit the scope for organisational changes have thus reduced the productivity gains from investment in ICT (Motohashi, 2005).

\section{Upgrading product market regulation and competition policy ${ }^{28}$}

32. The productivity gains from diffusing existing technology to lagging sectors can be as important as the gains resulting from the introduction of new technology. Stronger competition is one key to promoting the diffusion of technology. Although some progress has been made in revising the regulatory framework in Japan in recent years, further efforts at regulatory reform are essential. Reform should be based on the following principles. First, the regulatory framework should be reviewed and reformed continuously in line with changes in technology and other factors. For example, as the distinction between traditional broadcasting and telecommunication services weakens, regulations should be re-designed to facilitate the commercialisation of new ideas. Emerging industries often face regulatory barriers to commercialisation due to resistance from existing producers, consumers and government ministries. In particular, healthcare and nursing, education, and safety and security, which have been identified as examples of potential ICT-based services (OECD, 2005c), often face such barriers.

33. Conflict most frequently arises in Japan in the medical and welfare area, where the introduction of new services is often delayed on safety grounds. ${ }^{29}$ Japan has a relatively strong R\&D base in pharmaceuticals, as indicated by the number of researchers and articles published. However, regulations on the development and approval of new drugs in Japan are the strictest among the major five countries, preventing the results of R\&D from quickly benefiting society (Office of Pharmaceutical Industry Research, 2005b). The number of new medicines approved for sale in Japan is smaller than in other OECD countries and the delivery period of new drugs is more than two years longer than in the United States and the United Kingdom. ${ }^{30}$ Other important examples include the restriction on the sale of over-the-counter medicines in convenience stores, which has been limited by safety concerns, and the rule against the combined provision of insured and non-insured medical services. ${ }^{31}$ In sum, in order to maximise the

27. A negative correlation between the strictness of employment protection legislation and the share of investment spending devoted to ICT is pointed out in Jaumotte and Pain (2005a).

28. It should be noted that reforms in this area will enhance economic performance generally in addition to encouraging innovation.

29. Since 1982, 731 complaints regarding government regulations that hinder imports to Japan have been filed with the government's Office of Trade and Investment Ombudsman. The largest number of complaints, 243, concerned regulations by the Ministry of Health, Labour and Welfare.

30. Another report by the Office of Pharmaceutical Industry Research (2005a) ranked Japan 38th among 66 countries in the average delivery period of drugs following their introduction in the global market. The rapid development of new drugs is considered to be one of the most important factors in competitiveness (FTC, 2002).

31. In a new law (the Medical System Reform Law) prepared by the Minister of Health, Labour and Welfare together with the Minister of State for Regulatory Reform, the rules for the combined provision of insured and non-insured medical services have been reformed in order to make the process of introducing new technologies and drugs faster and less expensive. 
benefits of innovation, regulations and standards should be reformed swiftly based on strong political leadership.

34. Second, the Special Zones for Structural Reform initiative launched in 2003 should be used effectively to advance nation-wide regulatory reform. The special zone approach allows geographically limited areas to act as a testing ground for the implementation of reforms that are blocked at the national level (see the 2005 OECD Economic Survey of Japan). By November 2005, 547 regulatory reform proposals had been accepted. Of them, 206 have been tried in 709 special zones while the remaining 341 proposals were implemented nationwide from the beginning (Table 2). The decision on whether to extend the reforms in the special zones to the rest of the country is based on recommendations by the "Evaluation Committee". Thus far, 78 out of 206 reforms have been evaluated and 64 of them have been accepted on a nation-wide basis. However, it is still too early to judge the success of this initiative, which faces a number of obstacles. First, special interests may stall the implementation of key reforms in special zones. For example, although the management of hospitals by corporations was allowed for non-insured advanced treatments in the special zones in 2004, the special measure has been little used because of remaining regulatory constraints. Second, there is a risk that the extension of reforms on a nation-wide basis will be delayed. Reforms allowed in the zones should be applied on a nation-wide basis in a limited time period, avoiding unduly long periods of evaluation. Third, there is a risk that the special zone initiative will not lead to enough regulatory reform on a nation-wide basis as it may be too much affected by regional development considerations. Indeed, the same chief secretary is responsible for both the special zone initiative and regional development policies. To maintain the focus on nation-wide regulatory reform, the organisational link between the office for special zones and the office for regulatory reform should be strengthened.

Table 2. Reform proposals accepted nation-wide under the special zone initiative

\begin{tabular}{|c|c|c|c|}
\hline Ministry or agency & $\begin{array}{l}\text { Accepted in } \\
\text { special zones }\end{array}$ & $\begin{array}{c}\text { Accepted } \\
\text { nation-wide }\end{array}$ & Total \\
\hline National Public Safety Commission & 4 & 3 & 7 \\
\hline National Personnel Authority & 3 & 0 & 3 \\
\hline Financial Services Agency & 2 & 11 & 13 \\
\hline Ministry of Internal Affairs and Communications & $1 \overline{2}$ & 40 & 52 \\
\hline Ministry of Justice & 15 & 20 & 35 \\
\hline Ministry of Foreign Affairs & 2 & 9 & 11 \\
\hline Ministry of Finance & 7 & 18 & 25 \\
\hline Ministry of Education, Culture, Sports, Science and Technology & 35 & 33 & 68 \\
\hline Ministry of Health, Labour and Welfare & 35 & 86 & 121 \\
\hline Ministry of Agriculture, Forestry and Fisheries & 10 & 13 & 23 \\
\hline Ministry of Economy, Trade and Industry & 52 & 46 & 98 \\
\hline Ministry of Land, Infrastructure and Transport & 19 & 53 & 72 \\
\hline Ministry of the Environment & 9 & 8 & 17 \\
\hline Cabinet Office & 1 & 1 & 2 \\
\hline Total & 206 & 341 & 547 \\
\hline
\end{tabular}

Source: Office for the Promotion of Special Zones for Structural Reform. 
35. Third, prices in network industries, which are fundamental to almost all economic activities, remain high in Japan (see the 2004 Economic Survey of Japan). The fact that the price for Internet access is one of the lowest in the OECD area suggests that a more appropriate regulatory framework can lead to better outcomes. The government has implemented some important reforms in network industries, such as the introduction of number portability in the mobile phone sector from FY 2006 and expansion of retail choice for electricity consumers from $26 \%$ of the market in 2000 to $63 \%$ in 2005 . Such reforms are expected to reduce prices through enhanced competition. In order to ensure pro-active ex ante regulation, a necessary condition for competition in markets dominated by strong incumbents, most OECD countries have established sectoral regulators independent of the government, but Japan tries to achieve this through government ministries. The establishment of sectoral regulators independent of the government should be considered if the current approach does not work sufficiently well. In addition, previous OECD Economic Surveys recommended a number of reforms to enhance productivity in network industries, including: $i$ ) effective unbundling in the energy sector through legal or ownership separation; ii) reconsidering government ownership restrictions in the telecommunication sector; and iii) abolition of strict service obligation for new entrants in the postal sector, while ensuring the provision of universal postal services and preventing cream-skimming.

36. Fourth, there is significant scope for enhancing productivity in the retail and distribution industries. Despite a relaxation of regulations on the opening of large-scale retail stores, labour productivity in the retail sector in Japan is still only one-half of that in the United States (Figure 13). Low productivity is due to the small average size of retail stores, which limits the scope for economies of scale, making it difficult to benefit fully from new technologies and global supply chains. The small size of retail outlets, in turn, reflects the large number of traditional "mom-and-pop" type stores. Moreover, the productivity of traditional stores in Japan is significantly lower than that in the United States, offsetting the rather high productivity of discounters and general merchandise stores in Japan. There are a number of policies responsible for the small average size of stores in Japan:

i) regulations on new large-scale retail stores limit entry;

ii) elements of the tax system, including the low property tax, high capital gains tax and the exemption of inheritance taxes in the case of land, discourage the exit of mom-and-pop stores;

iii) government debt guarantees provided for SMEs under easy conditions; and

iv) traditional shops have benefited from the City Centre Revitalisation Law, which provides financial support to build car parks and other facilities.

The decline of traditional shopping areas, particularly in regional cities, in recent years has raised considerable political concern, resulting in some policy changes. For example, although the regulation on the location of liquor shops was removed in 2003, a new law limits the opening of liquor shops in areas where competition is severe. Moreover, new zoning regulations on the location of large-scale stores in suburban areas will be introduced in 2007. If this leads to entry barriers for large-scale stores, it will reduce competitive pressure on such stores already in operation, thus reducing benefits to consumers. 
Figure 13. Comparison of productivity in the retail sector by type of stores US average $=100$

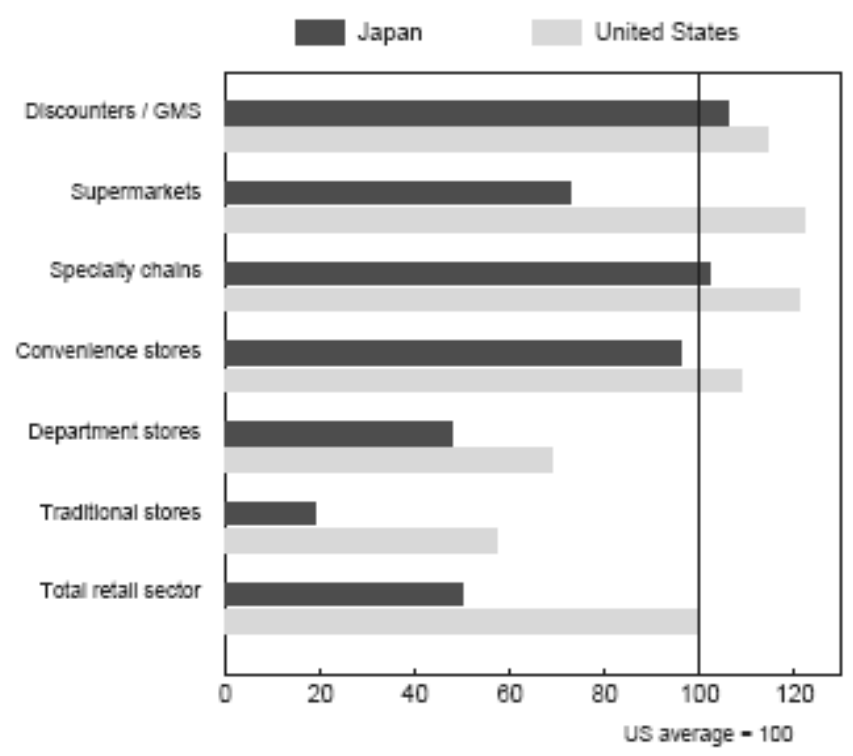

Source: McKinsey Global Institute (2000).

37. Fifth, ensuring fair competition is another aspect of promoting innovation. The revised AntiMonopoly Act that came into force in January 2006 has a number of positive features: $i$ ) it raised the level of surcharges imposed on violations of the law; ${ }^{32}$ ii) it established a leniency programme that provides total immunity to the first firm that voluntarily co-operates with the FTC in each case; iii) it introduced compulsory measures for criminal investigations; and iv) it improved investigation and hearing procedures. In addition, the staff of the Fair Trade Commission (FTC) has been increased by $5 \%$ at a time of budget cuts in other parts of the government. These reforms should allow the FTC to play a more active role, while strengthening the threat of criminal penalties. There have been only 13 criminal cases since 1950 and nobody has ever gone to jail for violating the competition law. There remains concern about whether the surcharges, which are still low by international standards, ${ }^{33}$ are an adequate deterrent. These issues are being addressed by the study group on competition policy established in the Cabinet Office in July 2005.

\section{Improving the system of intellectual property rights}

38. Protecting intellectual property rights (IPRs) strengthens incentives for innovation. However, empirical research shows that the relationship between the IPR system and innovative activity is complex (OECD, 2006b). The key to an effective IPR strategy is to achieve an appropriate balance between patent protection and the diffusion of technology and knowledge. ${ }^{34}$ In Japan, the patent system may err on the

32. The surcharge rate was increased to 6 to $10 \%$ for large manufacturers, 3 to $4 \%$ for small and medium-sized manufacturers, 2 to $3 \%$ for large retailers, and 1 to $2 \%$ for large wholesalers. In addition, a $50 \%$ surcharge was introduced for frequent violators.

33. In Europe, administrative fines can be as high as $10 \%$ of total firm turnover, rather than just the commerce affected, as in Japan. Fines in the United States may be up to two times the gain.

34. Japan introduced a new patent law in 2000 that was designed to make it easier for plaintiffs to prove patent infringement in court. A research group of METI recently reported that patents tend to discourage 
side of restricting diffusion as nearly two-thirds of the patents are idle (METI, 2002). Companies tend to hold a large number of patents simply to prevent their competitors from using certain technologies. In addition, the share of innovative patents in Japan is small, as patents are usually based on incremental changes in existing technologies (JPO, 1998). Another issue is the long waiting time for patent examination in Japan, partly due to a large number of requests for examination. METI has set an objective of reducing the exceptionally long waiting time for patent examination, which has recently increased to 27 months, to 11 months by 2013, primarily by hiring more staff (METI, 2006). In addition, it is considering discouraging companies from requesting examination of patents which may lack uniqueness and innovativeness. This objective, however, may require a further increase in the fees to have patents examined.

\section{Strengthening human capital development}

39. The supply of well qualified labour is a key ingredient in the generation and diffusion of innovation. The development of a labour force capable of adapting to new technology begins with a wellperforming compulsory school system. Japan has a high rate of student enrolment at all levels of education. By 2003, the proportion of the population between 25 and 34 years old with an upper secondary school education was the fourth highest in the OECD area and the second highest for tertiary education. High enrolment rates were accompanied by a high level of student achievement on international standardised tests, such as the OECD's PISA study, at least until 2000.

40. The level of student achievement, however, has declined according to the latest test results. In the PISA study, Japan's rank on mathematical literacy fell from first in 2000 to sixth in 2003, while its rank on reading dropped from eighth to fourteenth (OECD, 2004a). ${ }^{35}$ Such results have provoked a debate on whether the decline was due to the introduction of "stress free" (yutori) education, which resulted in a $17 \%$ fall in class hours for secondary students between 1969 and 1998. In addition, an OECD study found that 15-year-old students who are frequent computer users tend to perform better in key school subjects, particularly mathematics. Somewhat surprisingly, Japan has one of the lowest percentages of frequent computer users at school, with only $25 \%$ using a computer at least a few times a week, compared with more than $40 \%$ in 16 OECD countries (Figure 14). The attitude toward computers is also among the less positive group of countries in the OECD area (OECD, 2006a). The decline in test scores has not been stopped by the increase in the share of students attending private institutes for after-school tutoring (juku). By 2002, half of secondary school students, and $15 \%$ of second-year students in primary schools were enrolled in such institutes, according to one survey. The high and rising reliance on private tutoring at the primary and secondary level has a number of disadvantages (OECD, 2005h). First, it competes and overlaps with public education, thus raising total expenditures on education unnecessarily and imposing large financial burdens on families. Second, the high cost of private tutoring hinders equal access to educational opportunities, raising equity issues. Third, it makes it difficult for the public education system to cope with students of widely differing educational levels. Indeed, the OECD's PISA Study reported increasing stratification of results among students in Japan.

41. Moreover, the high dependence on private institutes for tutoring tends to hamper creativity and diversity in students. Such schools focus on techniques needed to get good scores on the entrance exams of upper secondary schools and universities, notably the nation-wide multiple-choice exam for university entry. Meanwhile, a government survey shows that the percentage of students in Japan who like science is

innovation in the software sector, and suggested the possibility of limiting patent rights in this area under certain conditions (METI, 2005).

35. The results of the Trends in International Mathematics and Science Study (TIMSS) by the International Association for the Evaluation of Educational Achievement (IEA) also show a decline in basic results in mathematics and science for primary and secondary school students (MEXT, 2004). 
only $55 \%$, as compared with the international average of $79 \%$, suggesting that standardised teaching methods may reduce student interest in some subjects.

\section{Figure 14. Percentage of students using a computer at least a few times each week}

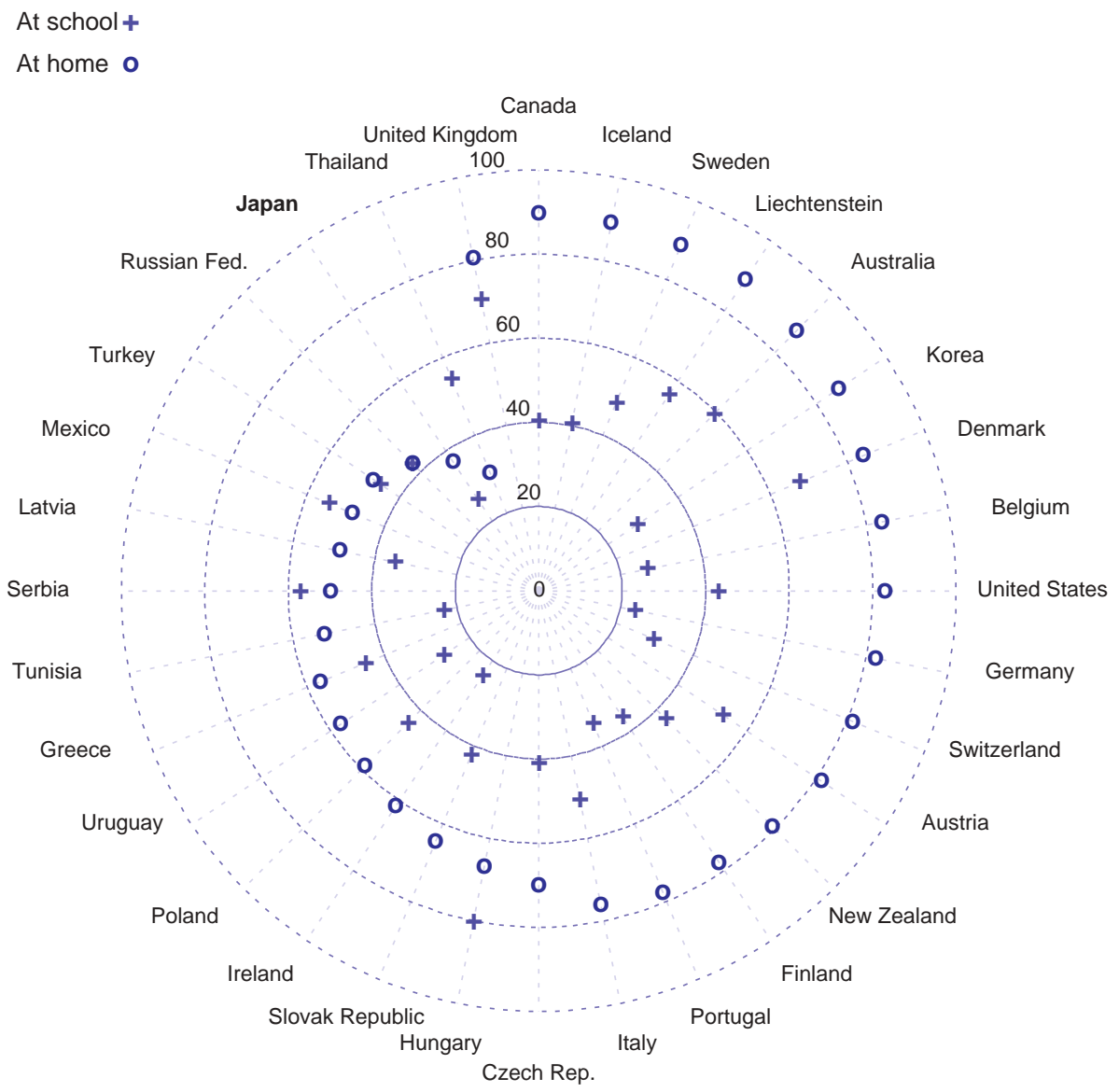

Source: OECD (2006a), Are students ready for a technology-rich world? What PISA tell us.

42. The government has allowed greater diversity in education through various measures, such as decentralising decision-making while increasing the accountability of those who teach in and manage schools. In addition, there have been a large number of proposals from local governments and business groups to relax regulations in education in the special zones. Among the 709 special zones approved through November 2005, 140 were related to the education sector. Most reforms focused on relaxing regulations on school management, facilities, curriculum and teachers' licences. In nearly half of the 140 zones, local governments are allowed to set a special curriculum, with English classes in primary schools the most popular case. ${ }^{36}$ Following positive results in the special zones, this measure was extended nation-wide. However, special zone initiatives must be funded by the responsible local authority. A more general approach that relaxes regulations imposed on spending funded by national grants is needed to enhance diversity in basic education and encourage competition among schools. At present, 370 local

36. Despite the national emphasis on learning English, Japan is ranked at the bottom in international tests, such as TOEFL, and the gap with other countries, such as Korea, is widening (ETS, 2001 2005). 
governments - about $15 \%$ of the total - have introduced or are considering a school-choice system that allows parents to choose elementary and lower secondary schools for their children.

43. The enrolment rate of tertiary education is high in Japan. However, based on a survey of business about their satisfaction with university education (IMD, 2005), Japan ranks only $56^{\text {th }}$ out of 60 countries evaluated. The primary role of universities appears to be screening students to help firms employ the brightest young people. Firms then play the key role in the human capital formation of their employees. This has significantly weakened the incentive for universities to improve the quality of education, while instead pursuing a "department store" style approach that offers a broad range of conventional courses. Moreover, the shift of resources from departments and courses with decreasing demand to those with increasing demand had been slowed by the rigid control imposed by the central government, contributing to the widening mismatch in labour demand and supply in recent years. ${ }^{37}$ However, flexibility has been enhanced since 2002 by allowing simple notification for re-organisation in certain cases. As the capacity of universities and junior colleges is expected to exceed the declining number of students by 2007, universities have to compete more vigorously for students by strengthening the courses in which they have a comparative advantage or which match local needs. Following recent reforms, universities are now allowed more flexibility to restructure, giving them the opportunity to become more relevant to the needs of in their specific regions. ${ }^{38}$

44. Opening the tertiary education market to accredited foreign providers would also be an effective way to stimulate competition and upgrade the competitiveness of Japanese universities. However, the number of branch campuses of foreign universities in Japan decreased from a peak of around 40 in the early 1990s to as low as four at present. Moreover, none have been recognised as a "university". The ministry created a new status of "foreign university" in December 2004 and so far four universities have been thus designated. However, except for one which is recognised as a Japanese specialised training college, three of these foreign universities do not benefit from the preferential tax treatment granted to Japanese universities, including exemption from the corporate and consumption taxes and the tax credit for donations, unless they are recognised as Japanese universities or specialised training institutes (ACCJ, 2004 and Market Access Ombudsman Council, 2005). In order to encourage competition among universities, the government should require greater disclosure about universities' management and performance so that students and businesses can evaluate the quality of universities more accurately and further reduce regulations, including those that prevent foreign universities from entering Japan.

45. As noted above, a key feature of human capital formation in Japan is the strong commitment of firms to job training. The practice of life-time employment, together with a steep wage profile based on seniority, penalises quits and effectively guarantees firms a return on their investment in the human capital of their employees. The government supports this approach by providing training subsidies to firms, while grants to individuals are very limited. Nevertheless, firms reduced the share of education and training in total labour costs from a peak of $0.38 \%$ in 1988 to $0.28 \%$ in 2002 (MHLW, 2003). While this reflects the impact of economic stagnation, an increasing number of firms consider human capital formation to be the responsibility of individual employees. At the same time, firms have expanded the share of part-time and other non-regular workers, a group that receives less training, raising both efficiency and equity concerns (see the 2006 OECD Economic Survey of Japan). The changing demand for job skills in the context of the

37. The job offer to applicant ratio has risen in recent years, surpassing unity, while the growth of employment has remained relatively modest.

38. For example, the establishment of management of technology (MOT) courses for employed persons people would increase the number of technology managers, who could play an important role in linking technology and management. METI is promoting an Entrepreneurship Promotion Programme to solicit proposals from universities to develop and evaluate MOT programmes in co-operation with industry (OECD, 2005e). 
shift to a knowledge-based economy suggests a rationale for a public role in lifelong learning. A coherent strategy, including a well functioning system of recognition and certification of learning, co-financing between public and private sources, quality control, and better policy co-ordination within government and between social partners is required (OECD, 2003a).

\section{Innovation-specific policies should be well targeted}

46. The government has implemented key reforms in recent years that have strengthened the links between the business sector and publicly-funded scientific research carried out in the 26 national research institutes, 51 independent administrative agencies and 89 national universities. The total size of the science and technology budget, including subsidies and grants to local governments and private institutes, was 3.6 trillion yen $(0.7 \%$ of GDP) in FY 2004. One of the most important reforms was the introduction in 1998 of Technology Licensing Offices (TLOs), which obtain patents for university researchers and licence them to private companies. Thus far, 47 TLOs have been established. Some are privately owned, while others are public-private partnerships. The government encourages their activities by reducing patent fees, allowing them free use of national university institutes, and providing subsidies for their operating costs. The number of patent applications submitted by the TLOs increased from 691 in 2000 to 4088 in 2003.

47. The government has also encouraged the creation of university-based venture firms by reorganising some government research institutes into "independent administrative agencies". The 51 research institutes given this status in FY 2001 have been granted increased autonomy in their financial and personnel decisions, while being subject to increased accountability through ex ante evaluations of plans, ex post evaluations of outcomes, and disclosure of financial statements. In addition, regulations on university professors have been gradually relaxed since 1997 to widen the possibility for them to work in private firms. Such opportunities were further enhanced by the re-organisation of the national universities into "national university corporations" in FY 2004. Professors, who were previously civil servants prior to the incorporation of universities, have much more freedom to interact with businesses and start their own firms. In addition, universities have more autonomy in hiring and promoting staff, and in making collaborative agreements with firms. Thanks to the establishment of TLOs and the incorporation of universities, the number of university-related venture businesses has risen from around 100 in 2000 to 1130 in 2005, exceeding the government's target of 1000 . Following their incorporation, national universities have been able to handle intellectual property rights by themselves, reducing the role for TLOs. In short, the important role played by the TLOs is being taken over by the universities themselves. It is thus necessary to streamline the TLOs and reduce their public subsidies.

48. Given the large share of public R\&D spending that is allocated to universities, a fair and transparent system to evaluate academic researchers is essential. Since the establishment of the National Institution for Academic Degrees and University Evaluation in 2000, the system has been improved by expanding capacity and improving evaluation methods. In order to increase transparency, the results of such evaluations should be made public as far as possible. However, given that the main obstacle to proper evaluation is the closed structure of the university employment system based on group loyalty, the key is to enhance the mobility of researchers as noted above.

49. In addition to funding public research, all OECD countries provide financial support to stimulate private-sector innovative activity via tax breaks for R\&D spending and/or direct subsidies. Since both approaches may impose deadweight losses, i.e. supporting activity that would have taken place even without public support, policies should be carefully designed. The effectiveness of individual instruments for financing business R\&D is highly contingent on their design and implementation, which vary significantly across OECD countries and even within individual countries (OECD, 2006b). 
50. The tax subsidy for R\&D in Japan in 2001 was close to zero but it had risen above the OECD average by 2004 (Figure 15). This is largely due to the introduction of a tax credit on R\&D and investment incentives in FY 2003, including temporary measures for three years, resulting in an estimated 1.1 trillion yen $\left(0.2 \%\right.$ of GDP) of foregone tax revenue per year. ${ }^{39}$ METI estimates that these tax cuts increased business investment by 3.7 trillion yen over the three-year period. In the FY 2006 budget, the temporary measures were largely terminated as scheduled. However, the R\&D investment incentive for SMEs was extended for another two years, while new measures, including a temporary tax incentive for acquiring information infrastructure, were introduced. ${ }^{40}$ As the foregone tax revenue from these measures is projected to be much smaller, at less than 0.2 trillion yen in total, than under the FY 2003 to FY 2005 scheme, the amount of corporate tax subsidies is likely to decline, particularly for large companies. This will widen the difference between the tax treatment of large companies and SMEs, who are already treated much more favourably. To promote innovation, tax subsidies for SMEs should be targeted on those facing difficulty in financing because of a lack of an established track record and tangible assets. However, current government support to SMEs, including subsidies and loans, is mainly targeted at revitalising existing enterprises or providing a safety net (OECD, 2005e). Although the government has expanded its support for start-ups, a further shift is needed in favour of newly established firms.

\section{A more integrated policy approach is needed to enhance innovation performance}

51. Given that the ultimate objective of innovation is to raise living standards, government programmes should be more focused on boosting productivity, rather than on upgrading technology itself. This requires greater linkages among policies for science and technology on the one hand and framework conditions, such as education, the product and labour markets, and competition policy on the other. First, the CSTP should emphasise the economic implications of science and technology policies while focusing more on framework conditions to enhance innovative activities. This would require increasing the number of economists in the expert panels and the secretariat. Furthermore, an additional expert panel should be created in the CSTP to analyse the economic impact of innovation in key areas and identify measures to increase its effectiveness through structural reforms and appropriate budget allocations. Second, stronger co-operation and co-ordination among ministries is required. For example, reports by the key advisory body on economic issues, the Council on Economic and Fiscal Policy (CEFP), have mentioned the importance of innovation in enhancing economic growth, while making few specific recommendations in

39. 1) The $R \& D$ tax credit: For corporate $R \& D$ activities, a proportional $R \& D$ tax credit of $8 \%$, plus $2 \%$ for the period FY 2003-05, of the amount of R\&D spending, was introduced. For corporations with a higher proportion of R\&D expenses, up to $2 \%$ of additional tax credit was applied. For SMEs, a proportional tax credit of $12 \%$, plus $3 \%$ for the period FY 2003-05, was introduced. For R\&D activities conducted jointly by academic, business and the government, a proportional tax credit of $12 \%$, plus $3 \%$ for the period FY 2003-05, was introduced. The scope of R\&D expenses qualified includes labour expenses, nonpersonnel expenses and depreciation for machinery and buildings and expenses of overseas R\&D activities. The amount of the R\&D tax credit cannot exceed $20 \%$ of the amount of corporation tax, although the excess may be carried over for one year under certain conditions. 2) The investment incentive for FY 2003 05 to promote IT investment in both hardware and software: Corporations could select a tax credit $(10 \%)$ or a special allowance for accelerated depreciation (50\%). The amount of tax credit cannot exceed $20 \%$ of the amount of corporation tax, although the excess may be carried over for one year under certain conditions. 3) Accelerated depreciation for R\&D investment for FY 2003-05: a special allowance (50\%) for depreciation for R\&D investment was applied.

40. Firms were able to receive the special tax credit for R\&D expenses for either total or incremental outlays. Under the new approach, the tax credit is based on total outlays. During FY 2006-07, there is an additional credit for $5 \%$ of the amount of incremental R\&D spending. As for the tax incentive for acquiring information infrastructure, firms can choose between special depreciation of $50 \%$ of the standard acquisition value or a special tax credit of $10 \%$ of that value for two years. 
this area thus far. ${ }^{41}$ Although a number of ministers, including the prime minister, are members of both the CEFP and the CSTP, the linkage between these two councils is limited in practice. The same is true concerning co-ordination between the CSTP and the Council for the Promotion of Regulatory Reform.

Figure 15. Tax treatment of R\&D in OECD countries(1)

Rate of tax subsidy for one unit of R\&D in 2004

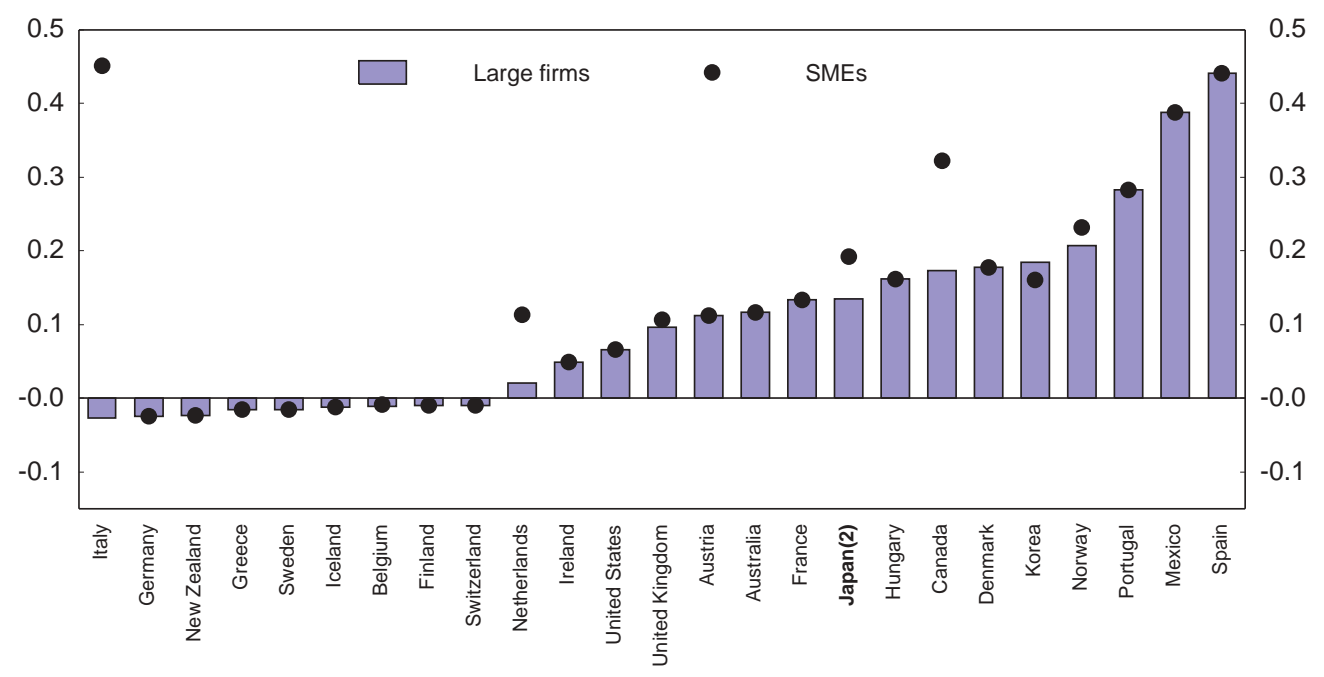

1. Tax subsidies are calculated as 1 minus the $B$ index, which is defined as the present value of before-tax income necessary to cover the initial cost of R\&D investment and to pay corporate tax. For example, in Spain, 1 unit of R\&D expenditure by large firms results in 0.44 unit of tax relief.

2. The $2004 \mathrm{~B}$ index for large firms in Japan applies to firms with a ratio of $R \& D$ to sales of less than $10 \%$. The $B$ index for large firms with an R\&D-to-sales ratio above $10 \%$ is 0.831 . The $B$ index for research conducted in collaboration with universities is 0.782 .

Source: OECD, OECD Science, Technology and Industry Scoreboard 2005.

\section{Conclusion}

52. Increasing the effectiveness of Japan's innovation system is essential to boost productivity growth to sustain the rise in living standards in the context of population ageing. Accomplishing this objective requires changes in science-related policies as well as in a wide range of framework policies. The recommendations made in this paper are summarised in Box 4. For recommendations related to increasing international openness, see Chapter 6 of the 2006 OECD Economic Survey of Japan.

41. Since the spring of 2006, the CEFP has been discussing policies to enhance growth potential and international competitiveness through innovation, with a focus on human resource development and service sector productivity. Specific recommendations will be made in June. 


\section{Box 4. Summary of recommendations to encourage innovation}

\section{Reform framework conditions to support innovative activities}

- $\quad$ Promote the development of venture capital markets by removing any obstacles to participation by pension funds, reducing the capital gains tax and focusing government policies on leveraging and diversifying private sources of capital, while moving away from public debt guarantees and finance.

- $\quad$ Scale back the size of public financial institutions and ensure a level playing field between the privatised Japan Post and private-sector financial institutions in order to reduce the flow of savings to the public sector, thereby enhancing the availability of funds for venture business and new start-ups.

- $\quad$ Enhance the mobility of labour, including researchers, in part through increasing the portability of pensions and reforming retirement allowances at public research institutes.

- $\quad$ Expand the use of open competition in hiring, performance-based pay and fixed-term contracts in order to enhance mobility and reduce "in-breeding" in public research institutes and universities.

Reduce labour practices that limit the scope for organisational changes that would allow firms to benefit more fully from introducing new technology.

Improve the regulatory framework continuously to reflect technological progress, particularly in the areas of medical and social welfare services, while further strengthening competition policy.

Upgrade the regulatory framework for network industries.

Boost productivity in the retail sector, in part by avoiding policies that favour small stores.

Use the special zone initiative to quickly advance nation-wide structural reforms and provide greater information on the nation-wide implementation of reforms and their economic impact.

- $\quad$ Further accelerate the evaluation of patents while making the system more efficient.

\section{Enhancing creativity in education and the diffusion of knowledge}

- $\quad$ Give more autonomy to local governments and individual schools in setting curriculum, hiring teachers and setting wages to increase competition between schools and reverse declining levels of performance.

- $\quad$ Reform the entrance examination system for secondary schools and universities to cover a broader range of knowledge.

- $\quad$ Encourage competition among universities by allowing more flexibility in their management, enhancing transparency in evaluating performance and further reducing regulations, including those that prevent foreign universities from entering Japan, while ensuring high quality education.

- $\quad$ Enhance vocational training by establishing a well functioning system of recognition and certification of learning that is co-financed by public and private sources.

\section{Upgrade the policy framework to improve innovation-specific policies}

- $\quad$ Strengthen links between public research institutes and the business sector.

- $\quad$ Avoid mixing national innovation policies with measures to promote balanced regional development.

- Increase further the share of competitive grants in the allocation of public R\&D funds.

- $\quad$ Attach greater importance to the non-manufacturing sector in the allocation of public R\&D funds.

- $\quad$ Maintain flexibility in allocating public R\&D funds, thereby limiting the risks inherent in concentrating R\&D efforts in the sectors identified as priority areas.

Focus support for R\&D on new start-ups.

Expand the CSTP's work to include framework measures to promote innovation. Strengthen the link with other councils, including the CEFP and the Council for the Promotion of Regulatory Reform, in formulating framework policies. 


\section{Bibliography}

American Chamber of Commerce in Japan (ACCJ) (2004), "Ensure a level playing field for Foreign University Japan Campuses", ACCJ Viewpoint, Tokyo.

Aoki, M. and H. Yoshikawa (2002), "Demand saturation-creation and economic growth", Journal of Economic Behaviour \& Organization, Vol. 48 (2002), Elsevier.

Ando, H. and K. Motohashi (2002), A Plan on Competitiveness of the Japanese Economy, Nihon Keizai Shimbunsha, Tokyo (in Japanese).

Baek, Yongchun and Randall S. Jones (2005), "Sustaining High Growth Through Innovation: Reforming the R\&D and Education Systems in Korea", OECD Economics Department Working Papers No. 470, Paris.

Cabinet Office (2002), Annual Report on the Japanese Economy and Public Finance, 2001-2002, Tokyo.

Cabinet Office (2005a), Annual Report on the Japanese Economy and Public Finance, 2005, Tokyo.

Cabinet Office (2005b), White Paper on the National Lifestyle 2005 - Perceptions and lifestyle of the child-rearing generation, Tokyo (in Japanese).

Carnegie Foundation for the Advancement of Teaching (1994), The academic profession: an international perspective, Stanford.

Council for the Promotion of Regulatory Reform (2005), Follow-up of the three-year deregulation plan, Tokyo.

Council for Science and Technology Policy (CSTP) (2003), Regarding creation and promotion of R\&D ventures: taking advantage of the strength in the Japanese technology potential, Tokyo (in Japanese).

Council for Science and Technology Policy (CSTP) (2005), Recommendations on the Science and Technology Basic Policy, Tokyo (in Japanese).

Council on Competitiveness (1999), The New Challenge to America's Prosperity, Washington D.C.

Council on Economic and Fiscal Policy (CEFP) (2002), Public financial institutions in four advanced countries. A report submitted to the Council by the Minister for Economic and Fiscal Policy on $2^{\text {nd }}$ of August, Tokyo (in Japanese).

Economic Planning Agency (EPA) (1999), Economic Survey of Japan, FY 1999, Tokyo (in Japanese).

Educational Testing Service (ETS) (2001 2005), TOEFL Test and Score Data Summary.

Evaluation Committee of the Special Zones for Structural Reform (2006), Recommendation on the special regulatory measures implemented in special zones for the second half of FY 2005, (in Japanese).

Fair Trade Commission (2002), A research on innovation competition and competition policy - An example of the pharmaceutical industry, Tokyo (in Japanese).

Fukao, K, and H. Kwon (2003), "Japan's Productivity and Economic Growth: an Empirical Analysis Based on Industry-Level and Firm-Level Data", ESRI Discussion Paper Series No. 66, Economic and Social Research Institute (ESRI), Cabinet Office, Tokyo (in Japanese).

Goto, A. (2000), Innovation and the Japanese Economy, Iwanami Shoten, Tokyo (in Japanese).

Government of Japan (2001), The Science and Technology Basic Plan (2001-2005), Tokyo, in Japanese.

Government of Japan (2006), The Science and Technology Basic Plan (2006-2010), Tokyo, (in Japanese). 
Harayama, Y. (2003), "Intermediaries in University-Industry Cooperation: Current Situation and Issues Concerning TLOs and Incubators", Stanford Japan Center Discussion Papers DP-2003-005-J, Palo Alto (in Japanese).

International Institute for Management Development (IMD) (2005), The World Competitiveness Yearbook 2005, World Competitiveness Center, IMD, Lausanne.

Japanese Bankers Association (2001), Recommendation for a fundamental reform of the public financial institutions, Tokyo (in Japanese).

Japan Patent Office (JPO) (1998), Towards further deepening of pro-patent policy, Planning Committee of the Industrial Property Council, Tokyo (in Japanese).

Japan Small and Medium Enterprise Corporation (JASMEC) (2002), Survey report on the direct financing environment for venture companies in Japan and other countries, Tokyo (in Japanese).

Jaumotte, F. and N. Pain (2005a), "From ideas to development: the determination of R\&D and patenting", OECD Economics Department Working Papers No. 457, Paris.

Jaumotte, F. and N. Pain (2005b), "Innovation in the business sector", OECD Economics Department Working Papers No. 459, Paris.

Kondo, M. (2006), "Evolving Roles of Japanese Public Research Institutes", Proceedings of The Fifteenth International Conference on Management of Technology (IAMOT 2006), Beijing, May.

Market Access Ombudsman Council (2005), Recommendation on Market Access Issues as Concerns Standards, Certifications and Others, 8th Report, Tokyo (in Japanese).

McKinsey Global Institute (2000), Why the Japanese economy is not growing: Micro barriers to productivity growth, Washington, D.C.

Ministry of Economy, Trade and Industry (METI) (2001), White Paper on International Economy and Trade, 2001, Tokyo.

Ministry of Economy, Trade and Industry (METI) (2002), Research and development activities in industrial technologies in Japan - Main indicators and research data, Tokyo (in Japanese).

Ministry of Economy, Trade and Industry (METI) (2004), N Report - Toward a New Industrial Structure, Tokyo (in Japanese).

Ministry of Economy, Trade and Industry (METI) (2005), An interim report of the Study Group on Legal Protection of Software and Promotion of Innovation, Tokyo (in Japanese).

Ministry of Economy, Trade and Industry (METI) (2006), Action plan on accelerating and raising efficiency in patent evaluation, Tokyo (in Japanese).

Ministry of Education, Culture, Sports, Science and Technology (MEXT) (2002), Annual Report on the Promotion of Science and Technology, FY 2002, Tokyo.

Ministry of Education, Culture, Sports, Science and Technology (MEXT) (2004), Trends in International Mathematics and Science Study 2003 by IEA, Tokyo (in Japanese).

Ministry of Education, Culture, Sports, Science and Technology (MEXT) (2005a), Annual Report on the Promotion of Science and Technology, FY 2005, Tokyo.

Ministry of Education, Culture, Sports, Science and Technology (MEXT) (2005b), Japan's Education at a Glance 2005, Tokyo (in Japanese).

Ministry of Health, Labour and Welfare (MHLW) (2003), White Paper on the Labour Economy, FY 2003, Tokyo (in Japanese). 
Ministry of Internal Affairs and Communications (MIC) (2001), A survey on the retirement allowances of private companies FY 2001, Tokyo (in Japanese).

Motohashi, K. (2005), Emprical Analysis of IT Innovation: Has IT Changed Long-term Japanese Economic Performance? Research Institute for Economy, Trade and Industry, Tokyo (in Japanese).

National Science Foundation (2004), Science and Technology Indicators 2004.

National Institute of Science and Technology Policy (NISTEP) (2005), Study for Evaluating the Achievements of the Science and Technology Basic Plans in Japan - Key Figures of the Study for FY 2003 and FY 2004, Tokyo.

National Institute of Science and Technology Policy (NISTEP) and Mitsubishi Research Institute (MRI) (2005), Study for Evaluating the Achievements of the Science and Technology Basic Plans in Japan - Main achievements and problems with the programmes related to human resource development in science and technology area, Tokyo (in Japanese).

Niimi, K. and Y. Okina (1995), "What factors are hampering the growth of venture businesses? - Towards establishing a Japanese business incubation system", Japan Research Review, May, The Japan Research Institute, Limited, Tokyo (in Japanese).

Nishimura, K., T. Nakajima and K. Kiyota (2003), "What happened to Japanese industry during the lost 1990s - Entry and exit of the Japanese firms and total factor productivity" RIETI Discussion Paper Series 03-J-002, Research Institute for Industry, Economy and Trade (RIETI), Tokyo (in Japanese).

Nishimura, K. G., and Y. Kawamoto (2003), "Why Does the Problem Persist? 'Rational Rigidity' and the Plight of Japanese Banks", The World Economy, Vol. 26, Blackwell Publishing Ltd, Oxford.

OECD (2001), The New Economy Beyond the Hype - The OECD Growth Project, Paris.

OECD (2003a), Beyond Rhetoric: Adult Learning Policies and Practices, Paris.

OECD (2003b), OECD Economic Survey of Japan, Paris.

OECD, (2003c), The Sources of Economic Growth in OECD Counties, Paris.

OECD (2004a), Learning for Tomorrow's World: First Results from PISA 2003, Paris.

OECD (2004b), OECD Economic Survey of Germany, Paris.

OECD (2004c), OECD Economic Survey of Japan, Paris.

OECD (2004d), OECD Science, Technology and Industry Outlook, Paris.

OECD (2005a), Education at a Glance 2005, Paris.

OECD (2005b), Enhancing the Performance of the Service Sector, Paris.

OECD (2005c), Governance of Innovation Systems, Vol.2: Case Studies in Innovation Policy, Paris.

OECD (2005e), Innovation Policy and Performance: A Cross-Country Comparison, Paris.

OECD (2005f), Main Science and Technology Indicators Database, Paris.

OECD (2005g), OECD Economic Survey of Japan, Paris.

OECD (2005h), OECD Economic Survey of Korea, Paris.

OECD (2005i), OECD Economic Survey of the United Kingdom, Paris.

OECD (2005j), OECD Science, Technology and Industry Scoreboard 2005, Paris.

OECD (2006a), Are students ready for a technology-rich world? - What PISA Studies tells us, Paris.

OECD (2006b), Economic Policy Reforms: Going for Growth, Paris. 
OECD (2006c), OECD Economic Survey of Japan, Paris.

Office of Pharmaceutical Industry Research (OPIR) (2005a), "Problem in Japan with the access to new drugs - Cross-country time lag before commercialisation", OPIR News No. 18, Tokyo (in Japanese).

Office of Pharmaceutical Industry Research (2005b), Strengthening competitiveness as a place for drug creation - Current situation and problems in the pharmaceutical industry, Tokyo (in Japanese).

Sakakibara, K. (2003), "Outlook report: Technology management in Japan - Is R\&D linked to management outcomes?", CISREP Discussion Paper Series \#03-01, Corporate Innovation System Renaissance Project, National Institute of Advanced Industrial Science and Technology, Tokyo.

Sakakibara, K. and M. Tsujimoto (2003), "Why did R\&D productivity of Japanese firms decline?" ESRI Discussion Paper Series No. 47, Economic and Social Research Institute, Cabinet Office.

Science Council of Japan (2005), "Recommendations on important issues of the Science and Technology Basic Plan, Review Committee of the Science and Technology Basic Plan", Tokyo (in Japanese).

Takahashi, F. (2006), "Current situation and problems with the Japanese venture capital - Comparison between Japan and the US", RIETI-CARF Policy Symposium, "What Financing Mechanisms and Organizations of Business Entities Best Facilitate Innovation?", Research Institute for Industry, Economy and Trade (RIETI) (in Japanese).

Todo, Y, and S. Shimizutani (2005), "Overseas R\&D Activities by Japanese Multinational Enterprises: Causes, Impacts, and Interaction with Parent Firms", ESRI Discussion Paper Series No. 132, Economic and Social Research Institute (ESRI), Cabinet Office.

United States Trade Representative (2006), National Trade Estimate Report on Foreign Trade Barriers.

Usukine, M. (1999), "Is the common view 'Defined contribution pension system has a positive impact on labour mobility’ true?” NLI Report December 1999, NLI Research Institute (in Japanese).

Venture Enterprise Center (2005), Survey report on venture capital investment in FY 2005/Survey report on fund benchmark, Tokyo (in Japanese).

Wakasugi, R., M. Yachi, Y. Wada, and F. Koyata (1995), "Research and Development, Innovation and Scale Economies: A Mystery", Trade and Industry Review, Research Institute for Trade and Industry, Tokyo (in Japanese). 
Annex 1

\section{International comparison of innovation performance}

The tables below show the individual country results for the indicators reported in Figure 2.

Table A1. Innovation indicators for individual countries

A. Input-related indicators (as per cent of GDP in 2003 ${ }^{1}$ )

\begin{tabular}{|c|c|c|c|c|}
\hline & $\begin{array}{c}\text { Gross domestic } \\
\text { expenditure on } R \& D\end{array}$ & $\begin{array}{c}\text { Share of business } \\
\text { R\&D }\end{array}$ & $\begin{array}{c}\text { Share of } \\
\text { government R\&D }\end{array}$ & $\begin{array}{l}\text { Share of higher } \\
\text { education } R \& D\end{array}$ \\
\hline Australia & 1.6 & 0.8 & 0.3 & 0.4 \\
\hline Austria & 2.2 & 1.5 & 0.1 & 0.6 \\
\hline Belgium & 2.3 & 1.7 & 0.1 & 0.4 \\
\hline Canada & 1.9 & 1.0 & 0.2 & 0.7 \\
\hline Czech Republic & 1.3 & 0.8 & 0.3 & 0.2 \\
\hline Denmark & 2.5 & 1.7 & 0.2 & 0.6 \\
\hline Finland & 3.5 & 2.5 & 0.3 & 0.7 \\
\hline France & 2.2 & 1.4 & 0.4 & 0.4 \\
\hline Germany & 2.6 & 1.8 & 0.3 & 0.4 \\
\hline Greece & 0.7 & 0.2 & 0.2 & 0.3 \\
\hline Hungary & 1.0 & 0.4 & 0.3 & 0.3 \\
\hline Iceland & 3.0 & 1.6 & 0.7 & 0.6 \\
\hline Ireland & 1.1 & 0.8 & 0.1 & 0.2 \\
\hline Italy & 1.2 & 0.6 & 0.2 & 0.4 \\
\hline Japan & 3.2 & 2.4 & 0.3 & 0.4 \\
\hline Korea & 2.6 & 2.0 & 0.3 & 0.3 \\
\hline Luxembourg & 1.7 & 1.6 & 0.1 & 0.0 \\
\hline Mexico & 0.4 & 0.1 & 0.2 & 0.1 \\
\hline Netherlands & 1.8 & 1.0 & 0.2 & 0.5 \\
\hline New Zealand & 1.2 & 0.5 & 0.4 & 0.3 \\
\hline Norway & 1.8 & 1.0 & 0.3 & 0.5 \\
\hline Poland & 0.6 & 0.2 & 0.2 & 0.2 \\
\hline Portugal & 0.9 & 0.3 & 0.2 & 0.3 \\
\hline Slovak Republic & 0.6 & 0.3 & 0.2 & 0.1 \\
\hline Spain & 1.1 & 0.6 & 0.2 & 0.3 \\
\hline Sweden & 4.0 & 3.0 & 0.1 & 0.9 \\
\hline Switzerland & 2.6 & 1.9 & 0.0 & 0.6 \\
\hline Turkey & 0.7 & 0.2 & 0.0 & 0.5 \\
\hline United Kingdom & 1.9 & 1.2 & 0.2 & 0.4 \\
\hline United States & 2.6 & 1.8 & 0.2 & 0.4 \\
\hline EU15 & 2.0 & 1.3 & 0.3 & 0.4 \\
\hline EU25 & 1.9 & 1.2 & 0.3 & 0.4 \\
\hline OECD weighted average & 2.2 & 1.5 & 0.2 & 0.4 \\
\hline
\end{tabular}

1. Or latest available year. 
ECO/WKP(2006)55

Table A1. Innovation indicators for individual countries (continued)

A. Input-related indicators (continued)

\begin{tabular}{|c|c|c|c|}
\hline & $\begin{array}{c}\text { Number of researchers per } \\
1000 \text { employed } \\
\left(2003^{1}\right)\end{array}$ & $\begin{array}{l}\text { Tertiary graduates as a } \\
\text { share of employment } \\
\qquad\left(2003^{1}\right)\end{array}$ & $\begin{array}{c}\text { Share of degrees in } \\
\text { science and engineering } \\
\left(2002^{1}\right)\end{array}$ \\
\hline Australia & 7.6 & 31.7 & 21.6 \\
\hline Austria & 5.8 & 15.2 & 28.0 \\
\hline Belgium & 8.4 & 35.3 & 23.1 \\
\hline Canada & 7.2 & 43.6 & 20.4 \\
\hline Czech Republic & 3.2 & 13.0 & 25.9 \\
\hline Denmark & 9.2 & 30.7 & 15.8 \\
\hline Finland & 17.7 & 35.5 & 29.0 \\
\hline France & 7.5 & 25.5 & 28.7 \\
\hline Germany & 6.9 & 24.6 & 30.9 \\
\hline Greece & 3.7 & 21.5 & - \\
\hline Hungary & 3.9 & 18.8 & 12.0 \\
\hline Iceland & - & 23.8 & 17.7 \\
\hline Ireland & 5.3 & 29.2 & 25.9 \\
\hline Italy & 3.0 & 13.0 & 22.8 \\
\hline Japan & 10.4 & 40.6 & 25.9 \\
\hline Korea & 6.8 & 31.6 & 38.6 \\
\hline Luxembourg & 6.2 & 16.7 & 31.5 \\
\hline Mexico & 0.6 & 17.1 & 23.6 \\
\hline Netherlands & 5.2 & 24.8 & 16.0 \\
\hline New Zealand & 9.1 & 28.6 & 19.8 \\
\hline Norway & 9.1 & 30.7 & 14.8 \\
\hline Poland & 4.5 & 18.3 & 11.0 \\
\hline Portugal & 3.5 & 11.7 & 18.1 \\
\hline Slovak Republic & 4.7 & 14.2 & 27.3 \\
\hline Spain & 5.6 & 30.0 & 24.3 \\
\hline Sweden & 10.6 & 33.3 & 31.0 \\
\hline Switzerland & 6.3 & 27.4 & 28.5 \\
\hline Turkey & 1.1 & 12.1 & 22.5 \\
\hline United Kingdom & 5.5 & 28.9 & 28.1 \\
\hline United States & 9.3 & 38.2 & 15.7 \\
\hline EU15 & 6.1 & 23.8 & 26.6 \\
\hline EU25 & 5.8 & - & - \\
\hline OECD weighted average & 6.6 & 29.0 & 23.1 \\
\hline
\end{tabular}

1. Or latest available year. 
ECO/WKP(2006)55

Table A1. Innovation indicators for individual countries (continued)

B. Output-related indicators

\begin{tabular}{|c|c|c|}
\hline & $\begin{array}{l}\text { Scientific articles per million } \\
\text { population (2001) }\end{array}$ & $\begin{array}{l}\text { Triadic patent families }{ }^{2} \text { per million } \\
\text { population }(2001)\end{array}$ \\
\hline Australia & 785.5 & 19.2 \\
\hline Austria & 563.5 & 34.9 \\
\hline Belgium & 582.0 & 42.1 \\
\hline Canada & 729.4 & 20.6 \\
\hline Czech Republic & 256.5 & 1.2 \\
\hline Denmark & 931.1 & 41.4 \\
\hline Finland & 982.7 & 98.5 \\
\hline France & 514.1 & 40.3 \\
\hline Germany & 529.8 & 90.7 \\
\hline Greece & 304.4 & 0.6 \\
\hline Hungary & 243.3 & 2.7 \\
\hline Iceland & 610.4 & 21.8 \\
\hline Ireland & 431.5 & 19.1 \\
\hline Italy & 385.4 & 14.8 \\
\hline Japan & 451.1 & 92.3 \\
\hline Korea & 233.1 & 10.6 \\
\hline Luxembourg & - & 46.5 \\
\hline Mexico & 32.1 & 0.2 \\
\hline Netherlands & 785.5 & 61.9 \\
\hline New Zealand & 742.1 & 9.5 \\
\hline Norway & 720.6 & 24.0 \\
\hline Poland & 148.7 & 0.2 \\
\hline Portugal & 208.1 & 0.6 \\
\hline Slovak Republic & 176.7 & 0.7 \\
\hline Spain & 386.7 & 2.9 \\
\hline Sweden & 1159.4 & 91.8 \\
\hline Switzerland & 1116.7 & 118.6 \\
\hline Turkey & 59.7 & 0.1 \\
\hline United Kingdom & 807.4 & 36.7 \\
\hline United States & 703.9 & 57.7 \\
\hline EU15 & 556.6 & 43.3 \\
\hline EU25 & 495.4 & - \\
\hline OECD weighted average & 467.7 & 41.5 \\
\hline
\end{tabular}

2. Patents filed at the European Patent Office (EPO), the US Patent \& Trademark Office (USPTO) and the Japanese Patent Office (JPO) to protect the same invention. 
ECO/WKP(2006)55

Table A1. Innovation indicators for individual countries (continued)

C. International integration (average of the period 1999-2001)

\begin{tabular}{|c|c|c|c|}
\hline & $\begin{array}{l}\text { Foreign ownership of } \\
\text { domestic inventions }^{3}\end{array}$ & $\begin{array}{l}\text { Domestic ownership of } \\
\text { foreign inventions }\end{array}$ & $\begin{array}{l}\text { Patents with foreign } \\
\text { co-inventors }\end{array}$ \\
\hline Australia & 24.4 & 12.2 & 18.6 \\
\hline Austria & 37.8 & 25.0 & 25.3 \\
\hline Belgium & 45.9 & 27.5 & 34.6 \\
\hline Canada & 34.4 & 30.4 & 30.4 \\
\hline Czech Republic & - & - & - \\
\hline Denmark & 23.2 & 16.0 & 18.5 \\
\hline Finland & 8.8 & 24.4 & 13.2 \\
\hline France & 21.8 & 17.9 & 15.0 \\
\hline Germany & 13.4 & 12.0 & 11.3 \\
\hline Greece & - & - & - \\
\hline Hungary & 52.4 & 15.7 & 34.4 \\
\hline Iceland & - & - & - \\
\hline Ireland & 37.7 & 40.8 & 30.7 \\
\hline Italy & 18.1 & 5.9 & 9.6 \\
\hline Japan & 3.7 & 3.7 & 2.9 \\
\hline Korea & 5.6 & 5.7 & 6.0 \\
\hline Luxembourg & 64.5 & 78.0 & 53.2 \\
\hline Mexico & - & - & - \\
\hline Netherlands & 20.5 & 30.5 & 14.9 \\
\hline New Zealand & 24.4 & 13.8 & 21.5 \\
\hline Norway & 23.6 & 19.4 & 21.3 \\
\hline Poland & - & - & - \\
\hline Portugal & - & - & - \\
\hline Slovak Republic & - & - & - \\
\hline Spain & 30.1 & 5.8 & 19.7 \\
\hline Sweden & 18.2 & 27.5 & 16.4 \\
\hline Switzerland & 23.6 & 47.8 & 29.9 \\
\hline Turkey & - & - & - \\
\hline United Kingdom & 37.5 & 18.4 & 21.5 \\
\hline United States & 12.1 & 17.4 & 11.6 \\
\hline EU15 & - & - & - \\
\hline EU25 & 11.4 & 7.6 & 7.4 \\
\hline OECD weighted average & 14.7 & 15.0 & 6.8 \\
\hline
\end{tabular}

3. Patent applications filed at the European Patent Office. 
Table A1. Innovation indicators for individual countries (continued)

\section{Other indicators}

\begin{tabular}{|c|c|c|c|c|}
\hline & $\begin{array}{c}\text { Share of business } \\
\text { R\&D that is } \\
\text { government financed } \\
\left(2003^{1}\right)\end{array}$ & $\begin{array}{c}\text { Knowledge-intensive } \\
\text { services }{ }^{4} \\
(2002)\end{array}$ & $\begin{array}{c}\text { Share of services } \\
\text { in business R\&D } \\
\left(2003^{1}\right)\end{array}$ & $\begin{array}{l}\text { Venture capital } \\
\text { investment }^{5} \\
(2000-03)\end{array}$ \\
\hline Australia & 4.3 & 22.2 & 47.1 & 0.13 \\
\hline Austria & 5.6 & 16.8 & - & 0.06 \\
\hline Belgium & 5.9 & 20.4 & 15.0 & 0.11 \\
\hline Canada & 2.6 & 17.4 & 37.4 & 0.29 \\
\hline Czech Republic & 12.0 & - & 35.2 & 0.06 \\
\hline Denmark & 3.1 & 15.3 & 40.0 & 0.12 \\
\hline Finland & 3.3 & 14.1 & 13.7 & 0.19 \\
\hline France & 10.3 & 20.6 & 11.6 & 0.12 \\
\hline Germany & 6.1 & 20.1 & 8.6 & 0.10 \\
\hline Greece & 1.2 & 11.7 & - & 0.05 \\
\hline Hungary & 6.4 & 16.4 & - & 0.03 \\
\hline Iceland & 1.4 & 15.8 & - & 0.51 \\
\hline Ireland & 3.0 & 16.9 & 31.7 & 0.11 \\
\hline Italy & 12.2 & 18.0 & 21.2 & 0.08 \\
\hline Japan & 0.8 & 16.5 & 7.0 & 0.03 \\
\hline Korea & 5.3 & 17.4 & 9.6 & 0.27 \\
\hline Luxembourg & 1.6 & 36.5 & - & - \\
\hline Mexico & 9.6 & 12.1 & - & - \\
\hline Netherlands & 4.3 & 21.4 & 20.4 & 0.20 \\
\hline New Zealand & 9.6 & 17.7 & & 0.09 \\
\hline Norway & 10.4 & 12.6 & 39.9 & 0.12 \\
\hline Poland & 15.2 & - & 13.4 & 0.06 \\
\hline Portugal & 2.1 & 15.4 & - & 0.08 \\
\hline Slovak Republic & 22.1 & - & - & 0.02 \\
\hline Spain & 11.1 & 14.5 & 28.5 & 0.12 \\
\hline Sweden & 5.9 & 16.5 & 10.6 & 0.26 \\
\hline Switzerland & 2.3 & 25.8 & - & 0.07 \\
\hline Turkey & 2.9 & - & - & - \\
\hline United Kingdom & 10.9 & 22.5 & 20.7 & 0.22 \\
\hline United States & 10.0 & 24.3 & 39.8 & 0.38 \\
\hline EU15 & 7.3 & 18.9 & 15.2 & 0.13 \\
\hline EU25 & 7.4 & 18.9 & 15.2 & 0.13 \\
\hline OECD weighted average & 7.2 & 20.3 & 25.4 & 0.26 \\
\hline
\end{tabular}

4. Share of total gross value added.

5. As per cent of GDP.

Source: OECD, Science, Technology and Industry Scoreboard, 2005. 
ECO/WKP(2006)55

\section{WORKING PAPERS}

The full series of Economics Department Working Papers can be consulted at www.oecd.org/eco/Working_Papers/

526. Strengthening the integration of Japan in the world economy to benefit more fully from globalisation (November 2006) Randall S. Jones and Taesik Yoon

525. OECD's FDI regulatory restrictiveness index: Revision and extension to more economies (November 2006) Sven Blöndal and Alain de Serres

524. Globalisation and inflation in the OECD economies (November 2006) Nigel Pain, Isabell Koske and Marte Sollie

523. Identifying determinants of Germany's international price competitiveness - A structural VAR approach (November 2006) Martin Meurers

522. Short-term pain for long-term gain: the impact of structural reform on fiscal outcomes in EMU (November 2006) Paul van den Noord and Boris Cournède

521. Interactions between monetary and fiscal policy: How monetary conditions affect fiscal consolidation (November 2006) Rudiger Ahrend, Pietro Catte and Robert Price

520. Restoring fiscal sustainability in the Euro Area: raise taxes or curb spending? (October 2006) Boris Cournède and Frédéric Gonand

519. Should Measures of Fiscal Stance be Adjusted for Terms of Trade Effects (October 2006) David Turner

518. Monetary policy and inflation expectations in Latin America: Long-run effects and volatility spillovers (October 2006) Luiz de Mello and Diego Moccero

517. Social safety nets and structural adjustment

(September 2006) Paul van den Noord, Nathalie Girouard and Christophe André

516. Adapting the Icelandic education system to a changing environment (September 2006) Hannes Suppanz

515. Forecasting monthly GDP for Canada (September 2006) Annabelle Mourougane

514. Finland's housing market: reducing risks and improving policies (September 2006) Laura Vartia

513. The Danish housing market: Less subsidy and more flexibility (September 2006) Espen Erlandsen, Jens Lundsgaard and Felix Huefner

512. Labour market reform in Germany: How to improve effectiveness (September 2006) Eckhard Wurzel

511. Removing obstacles to employment for women in Ireland (September 2006) Boris Cournède

510. Assessing Russia's non-fuel trade elasticities: Does the Russian economy react "normally" to exchange rate movements?

(September 2006) Christian Gianella and Corinne Chanteloup 


\section{ECO/WKP(2006)55}

509. Regulation, competition and productivity convergence (September 2006) Paul Conway, Donato De Rosa, Giuseppe Nicoletti and Faye Steiner

508. Improving education achievement and attainment in Luxembourg to compete in the labour market (September 2006) David Carey and Ekkehard Ernst

507. Raising economic performance by fostering product market competition in Germany (August 2006) Andrés Fuentes, Eckhard Wurzel and Andreas Reindl

506. Regulation of financial systems and economic growth (August 2006) Alain de Serres, Shuji Kobayakawa, Torsten Sløk and Laura Vartia

505. Enhancing Portugal's human capital

(August 2006) Bénédicte Larre and Stéphanie Guichard

504. Improving labour market performance in France

Améliorer la performance du marché du travail en France

(July 2006) Stéphanie Jamet

503. Wage setting in Finland: Increasing flexibility in centralised wage agreements (July 2006) Åsa Johansson

502. Taxation, business environment and FDI location in OECD countries (July 2006) Dana Hajkova, Giuseppe Nicoletti, Laura Vartia and Kwang-Yeol Yoo

501. The political economy of structural reform: Empirical evidence from OECD countries (July 2006) Jens Høj, Vincenzo Galasso, Giuseppe Nicoletti and Thai-Thanh Dang

500. Labour market performance, income inequality and poverty in OECD countries (July 2006) Jean-Marc Burniaux, Flavio Padrini and Nicola Brandt

499. Improving Public-Spending Efficiency in Czech Regions and Municipalities (July 2006) Philip Hemmings

498. Policies to Promote Innovation in the Czech Republic (July 2006) Alessandro Goglio

497. Getting Education Right for Long-Term Growth in the Czech Republic (July 2006) Alessandro Goglio

496. Assessing the 2005 Czech Proposals for Pension Reform (July 2006) Philip Hemmings and Edward Whitehouse

495. Poland's Education and Training: Boosting and Adapting Human Capital (July 2006) Paul O’Brien and Wojciech Paczynski 